1

\title{
Crystallization kinetics of clinopyroxene and titanomagnetite growing from a trachybasaltic melt: New insights from isothermal time-series experiments
}

Alessio Pontesilli ${ }^{1}$, Matteo Masotta ${ }^{2}$, Manuela Nazzari $^{3,4}$, Silvio Mollo $^{3,4}$, Pietro Armienti ${ }^{2}$, Piergiorgio Scarlato ${ }^{4}$, Marco Brenna ${ }^{1}$

${ }^{1}$ Department of Geology, University of Otago, PO Box 56, Dunedin 9054, New Zealand

${ }^{2}$ Dipartimento di Scienze della Terra, Università degli Studi di Pisa, Via S. Maria 53, 56126 Pisa, Italy

${ }^{3}$ Dipartimento di Scienze della Terra, Sapienza-Università di Roma, P.le Aldo Moro 5, 00185

Roma, Italy

${ }^{4}$ Istituto Nazionale di Geofisica e Vulcanologia, Via di Vigna Murata 605, 00143 Rome, Italy

\section{Corresponding author:}

Alessio Pontesilli

Department of Geology,

University of Otago,

PO Box 56,

Dunedin 9054,

New Zealand

Email: alessio.pontesilli@postgrad.otago.ac.nz 


\section{Abstract}

In order to investigate the role of crystallization kinetics in mafic alkaline systems, textural measurements, mineral compositional changes and diffusion modelling calculations have been carried out on isothermal time-series experiments. The data were obtained at $400 \mathrm{MPa}$ and $1,100{ }^{\circ} \mathrm{C}$ under anhydrous (nominally 0 wt. $\% \mathrm{H}_{2} \mathrm{O}$ ) and hydrous $\left(2 \mathrm{wt} . \% \mathrm{H}_{2} \mathrm{O}\right.$ added) conditions. A synthetic trachybasaltic melt was first heated up to the superliquidus temperature of $1,300{ }^{\circ} \mathrm{C}$ and then rapidly cooled at $80{ }^{\circ} \mathrm{C} / \mathrm{min}$ down to $1,100{ }^{\circ} \mathrm{C}$. The final target temperature was kept constant over variable dwell times in the range of 0.5-24 h. Estimates of area fractions, crystal sizes, crystal size distributions and surface area to volume ratios indicate the attainment of fast crystal growth kinetics at the shortest experimental run duration, with early achievement of stable crystal sizes for clinopyroxene and titanomagnetite. The surface area to volume ratio weakly decreases with increasing dwell time, according to the development of euhedral crystal morphologies. Crystal growth rates are also observed to progressively decrease from 0.5 to $24 \mathrm{~h}$. Due to the effect of fast growth kinetics, the morphological maturation of clinopyroxene progresses by attachment of dendrite branches, infilling and overgrowth phenomena, leading to the formation of well-faced and euhedral crystals. The kinetically-controlled cation exchange $(\mathrm{Si}+\mathrm{Mg}) \rightarrow\left({ }^{\mathrm{T}} \mathrm{Al}+\mathrm{Fe}^{3+}\right)$ controls the clinopyroxene compositional variation, expanding the stability of Tschermak component at the expense of diopside. Conversely, titanomagnetite is characterized by an almost constant composition that, however, is enriched in incompatible $\mathrm{Al}$ and $\mathrm{Mg}$ cations, as typically observed under rapid crystal growth conditions. Titanomagnetite crystals show always euhedral morphology that develops by heterogeneous nucleation on early-formed clinopyroxene dendrites. With increasing dwell time, the textural maturation of clinopyroxene reduces the number of heterogeneous nucleation sites and the titanomagnetite growth proceeds by coarsening. Overall, the effect of undercooling causes strong supersaturation phenomena in the trachybasaltic melt, resulting in enhanced nucleation kinetics and fast attainment of a high crystallinity. As the dwell time increases, the bulk system tends to minimize the interfacial free energy between crystals and surrounding melt. This results in the progressive replacement of the early dendritic shapes developed in a diffusion-limited growth regime, by the formation of euhedral morphologies typical of interface-limited regimes that still retain the chemical evidences of the dendritic stage as complex zoning patterns in clinopyroxene.

Keywords: Crystallization kinetics; undercooling; clinopyroxene; titanomagnetite; textural analysis; rapid crystal growth 


\section{Introduction}

The textural features of igneous rocks represent a valuable source of information for better understanding the physicochemical conditions of magmas at which crystals nucleate and grow (e.g. Cashman 1990, 1993; Armienti et al., 1994, 2013; Cashman and Blundy, 2000; Hammer, 2006, 2008; Resmini, 2007; Armienti, 2008). In this context, crystallization kinetics exert an important role in the solidification of the melt into a rock (e.g. Cashman and Marsh, 1988; Marsh, 1988, 1998; Hersum and Marsh, 2006; Higgins, 1998, 2006; Zieg and Lofgren, 2006; Spillar and Dolejs, 2013; Mollo and Hammer, 2017). A great number of experimental studies has been conducted on either natural or synthetic silicate liquids of variable compositions, in order to provide constraints on the textural and chemical changes of minerals under the effects of variable degrees of undercooling caused by either cooling (e.g., Lofgren et al., 1974; Donaldson, 1976; Walker et al.,1976, 1978; Kirkpatrick, 1981; Lofgren and Russell, 1986; Pupier et al., 2008; Del Gaudio et al., 2010; Mollo et al., 2011, 2012a, 2013a, 2013b; Iezzi et al., 2013) or decompression (e.g., Hammer and Rutherford, 2002, Couch et al., 2003; Hammer, 2008; Brugger and Hammer, 2010a; Waters et al., 2015). Undercooling, expressed as the difference between the liquidus and experimental temperatures $(\Delta \mathrm{T}$ $=\mathrm{T}_{\text {liq }}-\mathrm{T}_{\exp }$ ), can be experimentally controlled by either varying the liquidus temperature (by changing the melt $\mathrm{H}_{2} \mathrm{O}$ content) or the final target temperature (by applying variable cooling rates) (cf. Hammer, 2008; Mollo \& Hammer, 2017). Ostwald ripening, crystal coalescence, grain boundary migration, and infilling of early crystal framework are primary controlled by the undercooling and documented as the effective mechanisms controlling the textural features of the experimental products (Hammer and Rutherford, 2002; Simakin et al., 2003, Zieg and Lofgren, 2006; Pupier et al., 2008; Schiavi et al., 2009; Mollo at al., 2010; Iezzi et al., 2011, 2014; Ni et al., 2014; Welsch et al., 2014; Shea et al., 2015). The significance of these textural maturation mechanisms has been also assessed through specifically designed laboratory (Park and Hanson, 1999; Cabane et al., 2001, 2005) and natural (Higgins, 1998, 1999; O’Driscoll et al., 2007; Higgins and Roberge, 2003; Mollo et al., 2015a) investigations, as well as through experimental analogs (Means and Park, 1994) and numerical modelling (Hersum and Marsh, 2006). However, in spite of this extensive literature, a few experimental studies have clearly addressed the role of relaxation kinetics on crystal growth when the resting temperature is kept constant over different dwell times, after an early stage of undercooling (cf. Mollo et al., 2012a).

In this study, we present new textural and chemical data on clinopyroxene and titanomagnetite crystals obtained through isothermal time-series experiments conducted on a synthetic trachybasalt rapidly undercooled before crystallization. The imposed degree of undercooling is the thermodynamic driving force inducing early nucleation of clinopyroxene and 
titanomagnetite, whilst the crystal growth and textural maturation proceeded isothermally over time. The effects of crystallization kinetics and possible equilibration phenomena with increasing dwell time are quantified in terms of mineral and glass compositions, total crystallinity, maximum crystal size, and crystal size distribution analysis. Textural data are also compared with the diffusion length of chemical elements in the melt (i.e., modeling data from Zhang et al., 2010), in order to discriminate the influence of diffusion- and interface-limited growth on the disequilibrium or nearequilibrium compositions of minerals (Lofgren et al., 2006; Hammer, 2008; Watson \& Muller, 2009; Mollo and Hammer, 2017), and the potential relationship with observed crystal morphologies (Sunagawa, 1981, 2005; Faure et al., 2007). This comparative approach provides new insights on the solidification behavior of mafic alkaline magmas.

\section{Methods}

\subsection{Experiments}

The time-series experiments were conducted at the HP-HT Laboratory of Experimental Volcanology and Geophysics of the Istituto Nazionale di Geofisica e Vulcanologia (INGV) in Rome, Italy. A synthetic trachybasaltic starting material was obtained in batches of $\sim 2$ gr from pure oxides and carbonates mixed by grinding under ethanol in an agate mortar for $\sim 1 \mathrm{~h}$. This mixture was chosen in order to reproduce one of the most primitive products erupted at Mt. Etna volcano (i.e., the Mt. Maletto formation in Sicily, Italy; Armienti et al., 1988, 2013; Mollo et al., 2015b), as well as mafic alkaline magmas from different and complex intraplate settings in the world (cf. Mollo et al., 2018). A Pt-crucible containing the synthetic powder was loaded in a 1 atm vertical tube $\mathrm{CO}-\mathrm{CO}_{2}$ gas-mixing furnace at the $\mathrm{NNO}+2$ buffer. The temperature was kept at $1,100{ }^{\circ} \mathrm{C}$ for $10 \mathrm{~h}$ to ensure decarbonation and then was raised up to $1,600{ }^{\circ} \mathrm{C}$. This temperature was kept constant for $4 \mathrm{~h}$ to ensure homogeneous melting. The resulting glass was removed from the Ptcrucible and powdered. Backscattered microphotographs and microprobe analyses performed on chips extracted from top, middle, and bottom of the Pt-crucible, demonstrated homogeneity and the absence of crystalline phases in a glass with an average composition (in wt.\%) of $\mathrm{SiO}_{2}=50.09$ ( \pm 0.29$), \mathrm{TiO}_{2}=1.49( \pm 0.1), \mathrm{Al}_{2} \mathrm{O}_{3}=15.92( \pm 0.18), \mathrm{FeO}=8.09( \pm 0.13), \mathrm{MgO}=7.60( \pm 0.16), \mathrm{CaO}$ $=11.97( \pm 0.20), \mathrm{Na}_{2} \mathrm{O}=3.26( \pm 0.12), \mathrm{K}_{2} \mathrm{O}=1.53( \pm 0.09)$, and $\mathrm{P}_{2} \mathrm{O}_{5}=0.02( \pm 0.02)$. In order to minimize iron loss, some aliquots of the powder were previously loaded into the Pt-crucible and run for $3 \mathrm{~h}$ at $1,600{ }^{\circ} \mathrm{C}$ to pre-saturate the crucible (cf. Conte et al., 2006). The sample holder was then quenched and cleaned in a hot HF solution. The same approach was adopted to pre-saturate the Pt- 
capsules ( $3 \mathrm{~mm}$ of outer diameter) used for the piston cylinder experiments conducted at $400 \mathrm{MPa}$. It is found that the iron loss from the samples was kept to $<5 \%$ of the initial amount.

Piston cylinder experiments were carried out with a non-end loaded apparatus ("QUICKpress", Depths of the Earth co.) using a 19-mm NaCl-pyrex-graphite-MgO assembly that produced a redox state close to the NNO+2 buffer (Masotta et al., 2012). The assembly was simultaneously loaded with two Pt-capsules containing the nominally anhydrous (dried in oven at $110{ }^{\circ} \mathrm{C}$ for $48 \mathrm{~h}$ ) and hydrous ( $2 \mathrm{wt} . \%$ of deionized $\mathrm{H}_{2} \mathrm{O}$ added with a microsyringe) trachybasaltic glass. The capsules were also surrounded by powdered pyrophyllite to prevent $\mathrm{H}_{2} \mathrm{O}$ loss and enhance stress homogenization during initial compression (Freda et al. 2001, 2008). After cold pressurization to a nominal pressure $10 \%$ higher than desired, the pressure was decreased down to $400 \mathrm{MPa}$, after reaching the final resting temperature. Reversal experiments were carried out by isobarically superheating the starting glass from room temperature up to the superliquidus condition of $1,300{ }^{\circ} \mathrm{C}$ (the liquidus temperature of the trachybasalt is $\sim 1,200{ }^{\circ} \mathrm{C}$; Del Gaudio et al., 2010; Mollo et al., 2010, 2011) at a rate of $80^{\circ} \mathrm{C} / \mathrm{min}$. This temperature was kept constant for $30 \mathrm{~min}$ and then decreased down to the target crystallization condition of $1,100{ }^{\circ} \mathrm{C}$ using the same rate of 80 ${ }^{\circ} \mathrm{C} / \mathrm{min}$. At the superliquidus temperature of $1,300{ }^{\circ} \mathrm{C}$, the relaxation time to reach equilibrium is much shorter than the $30 \mathrm{~min}$ for the used trachybasaltic melt (Webb, 1997). For this starting melt composition and the used experimental strategy, relaxation kinetics are extremely rapid in time (i.e., from milli- to micro-seconds) and weakly dependent on the superheating path used in laboratory (Vetere et al., 2013, 2015).The temperature was monitored by a factory-calibrated C-type (W5Re/W-26Re) thermocouple with precision of $\pm 3{ }^{\circ} \mathrm{C}$. Considering the limited effect of 2 wt. $\% \mathrm{H}_{2} \mathrm{O}$ on the liquidus region of the trachybasaltic melt, the cooling path produced a nominal undercooling condition relatively fast $\left(\Delta T \approx 100-120^{\circ} \mathrm{C}\right)$, as previously experimentally demonstrated for similar starting compositions (Mollo et al., 2013a, 2013b, 2013c). $\Delta T$ refers to the difference between the phase-in temperature of the melt and the quench temperature. The isothermal condition was kept constant over variable dwell times of $0.5,1,2,4,8$, and $24 \mathrm{~h}$ (Table 1$)$. Then, an isobaric quench of $100{ }^{\circ} \mathrm{C} / \mathrm{s}$ was applied.

\subsection{Analyses}

Microchemical analyses (Table 1S, 2S and 3S) were performed at the HP-HT Lab of INGV using an electron probe microanalyzer (EPMA) Jeol-JXA8200 with combined EDS-WDS (five spectrometers with twelve crystals). Data were collected using $15 \mathrm{kV}$ accelerating voltage and 10 $\mathrm{nA}$ beam current. For glasses, a slightly defocused electron beam with a size of $5 \mu \mathrm{m}$ was used, with a counting time of $5 \mathrm{~s}$ on background and $15 \mathrm{~s}$ on peak. For crystals, the beam size was $5 \mu \mathrm{m}$ 
with a counting time of 20 and $10 \mathrm{~s}$ on peaks and background respectively. The following standards were used: jadeite ( $\mathrm{Si}$ and $\mathrm{Na})$, corundum $(\mathrm{Al})$, forsterite $(\mathrm{Mg})$, andradite $(\mathrm{Fe})$, rutile $(\mathrm{Ti})$, orthoclase $(\mathrm{K})$, apatite $(\mathrm{P})$, and spessartine $(\mathrm{Mn})$. Sodium and potassium were analyzed first to minimize alkali migration effects. The precision of the microprobe was measured through the analysis of wellcharacterized synthetic oxide and mineral secondary standards. Based on counting statistics, analytical uncertainties relative to their reported concentrations indicate that precision was better than $5 \%$ for all cations.

\subsection{Image processing and textural parameters}

Microphotographs were collected in backscattered electron (BSE) mode of a field emission gun-scanning electron microscopy (FE-SEM) Jeol 6500F equipped with an energy-dispersive spectrometer (EDS) detector and installed at the HP-HT Lab of INGV. Magnifications from $50 \times$ to $400 \times$ were adopted to collect a statistically representative number of crystals (i.e., clinopyroxene and titanomagnetite) for each different experimental charge. The ImageJ software package was used for image processing. Textural data were determined by thresholding (i.e., segmentation, as showed in Fig.1), counting, and measuring the crystal edges (e.g. Hammer et al., 1999; Brugger and Hammer, 2010a). According to the stereological theorem of Delesse (1847), the area fraction of the minerals investigated equals their volume fraction, provided that the distribution of crystals remains uniform along the entire length of the experimental capsule. Boundaries between touching crystals were identified through the visual inspection of the crystal shapes. The uncertainty introduced by this refining process was considered negligible due to the statistically high number of particles examined for each experimental capsule: 266-1,277 and 376-1,914 crystals for clinopyroxene and titanomagnetite, respectively. The uncertainty related to the quantification of the textural parameters was calculated as $1 \sigma$ variation of different crystal populations (Tables 2 and 3), thus representing sample heterogeneity rather than the error caused by image processing. A different approach is employed for estimating the uncertainty associated with area fraction (\%) measurements. It is apparent that the segmentation process represents the main potential source of error in estimating area fraction, especially for crystals with shapes characterized by high surface-to-volume ratios (e.g. dendritic crystals). Therefore, for each sample, we considered positive and negative errors in area fraction estimates that would arise from addition and subtraction of a pixel layer around each crystal in the binary image.

In the case of clinopyroxene, dendritic crystals characterize most of the experimental charges and their multiple intersection with the section plane impeded any reliable crystal size distribution (CSD) analysis (Hammer, 2006; Higgins, 2006; Armienti, 2008). Conversely, other 
textural parameters can be effectively quantified in terms of the dimensions of largest crystals (i.e., best-fit ellipse major and minor axis; Fig. 2), the surface area to volume ratio, and the volume fraction. The maximum growth rate $\left(G_{\text {max }}\right)$ of clinopyroxene was measured following one of the most common methods reported in literature (Burkhard, 2002; Hammer and Rutherford, 2002; Couch et al., 2003; Baker, 2008; Iezzi et al., 2011):

$$
G_{\max }=(L W)^{0.5} /(2 t)
$$

Where $L$ and $W$ are the mean length and width, respectively, on the basis of the ten largest crystals for each BSE image, whereas $t$ is the dwell time. The factor 2 refers to the growth of half-crystal during advancement of the pinacoid face. To track the textural evolution of clinopyroxene as a function of dwell time, the surface area to volume ratio $\left(S_{v}^{P}\right)$ has been also determined according to the method outlined by Hammer $(2006,2009)$ :

$S_{v}^{P}=S_{v} / \phi$

and

$S_{v}=2 N_{L}$

Where $S_{v}$ and $\phi$ are the total interfacial area of the population per unit volume of sample and the fractional volumetric phase abundance. $N_{L}$ is the mean number of boundary intersections per unit length of randomly-oriented test line (cf. Underwood, 1968). The parameter $S_{v}^{P}$ represents the ratio of crystal population surface area to the volume of that population, thus accounting for the difference in volumetric abundances among distinct crystal populations and/or BSE images. This parameter allows to quantify the textural maturation based on the crystal morphology. Moreover, $S_{v}^{P}$ can be hypothetically related to the crystallization conditions of the system (i.e., diffusion- and interface-limited crystallization phenomena), as long as it represents an estimate of the interfacial area developing between the crystal surface and surrounding glass feeding the crystal growth (Lofgren, 1974; Hammer and Rutherford, 2002).

In the case of titanomagnetite, the majority of crystals exhibits well-developed, euhedral morphologies enabling reliable CSD analysis. The crystal growth was investigated through the application of three different methods based on the assumption of constant growth kinetics over the adopted dwell time (e.g., Marsh, 1988; Armienti, 2008). In Method 1, $G_{\max }$ was determined 
$\begin{aligned} & 1246 \\ & 16\end{aligned} \quad d=\sqrt{\frac{\phi}{N_{A}}}$

1747

1348

2249

22

2250 2010b):

$G=d / 2 t$

and

and

following the same approach used for clinopyroxene. In Method 2, the batch growth rate $(G)$ was determined through the expressions (Blundy and Cashman, 2008; Brugger and Hammer, 2010a,

$N_{V}=N_{A} / d$

Where $d, t, \phi, N_{A}$, and $N_{V}$ are, respectively, the characteristic crystal size, the experimental time, the area fraction, the area number density (i.e., total number of crystals per unit area), and the volumetric number density. In Method 3, the CSD analysis was performed according to the procedure reported in Armienti (2008), where the stereological correction accounts for the "unfolding" method based on the algorithms of Schwartz (1939) and Saltykov (1949). This allows to consider the cut-section effects (i.e., larger particles contribute to smaller size classes when sectioned by a plane not passing through their center) and intersection-probability effects (i.e., smaller particles are less likely intersected by the section plane; Higgins, 2000, 2006). Despite the shape of CSD curves is strongly dependent on the choice of the bin size, the procedure of Armienti (2008) is optimized by including a routine properly designed for the minimization of the residuals between the measured number of particles and that re-calculated from the CSD (zeroth moment of the distribution) analysis as follow:

$N_{\text {tot }}=\operatorname{Area} \Sigma L_{i} N_{V}\left(L_{i}\right)$

and between the measured volume crystal fraction and that resulting from the CSD (third moment of the distribution):

$V_{f}=\sum N_{V}\left(L_{i}\right) \frac{4}{3} \pi\left(\frac{L_{i}}{2}\right)^{3}=\frac{\pi}{6} \sum L_{i}^{3} N_{V}\left(L_{i}\right)$ 
Subsequently, the CSD plot is formulated for a given image and the slope of this distribution is determined. The growth rate and the characteristic crystal size were calculated as the ratio between the total length and total number of crystals, expressed as the integral forms of the first and zeroth

and

Slope $=-\frac{1}{G t}=-\frac{1}{L_{d}}$

Where $n^{0}$ represents the value of the intercept at $L=0$ and $L_{d}$ is the characteristic crystal size. Note that $L_{d}$ is different from $d$ that, in turn, is the characteristic crystal size determined by the "batch" calculation approach.

\section{Results}

\subsection{Textural data}

\subsubsection{Crystal morphologies}

Clinopyroxene is the dominant mineral phase in the whole set of experiments (Fig. 3), with area fraction ranging from $35.8 \%$ to $53.5 \%$ (Table 2 and Fig. 4a). The comparison between anhydrous and hydrous experiments does not show relevant differences in the clinopyroxene content, neither illustrates any significant nor systematic variation with dwell time. Indeed, most of the area fraction measurements overlap within their associated uncertainties (Table 2 and Fig. 4a). Crystal morphologies are prevalently dendritic from 0.5 to $8 \mathrm{~h}$, whereas well-developed textures are observed at $24 \mathrm{~h}$ (Figs. 2 and 3). A marked difference in the crystal habit is recognizable between anhydrous and hydrous conditions, with more euhedral and faceted clinopyroxenes found in hydrous experiments (Fig. 3). The mean maximum size of clinopyroxene ranges from $54 \mu \mathrm{m}(0.5 \mathrm{~h})$ to $86 \mu \mathrm{m}(24 \mathrm{~h})$ and from $63 \mu \mathrm{m}(0.5 \mathrm{~h})$ to $120 \mu \mathrm{m}(24 \mathrm{~h})$ in the anhydrous and hydrous charges, respectively (Fig. 4b). A significant increase in the crystal size occurs only at $24 \mathrm{~h}$ and this is particularly evident under hydrous conditions. The $S_{v}^{P}$ parameter does not substantially change at 
$0.5,1$, and $2 \mathrm{~h}$, but then starts to decrease as the dwell time increases (Fig. 5). Values of $S_{v}^{P}$ measured under hydrous conditions are, on average, lower than those measured for the anhydrous charges. A marked difference can be observed at $24 \mathrm{~h}$ (Fig. 5), where the lower $S_{v}^{P}$ value of hydrous crystallization experiments reflects a higher degree of crystal euhedrality.

Titanomagnetite is scarce in the experimental charges, with area fractions variable from $0.5 \%$ to $2.5 \%$ and from $1.4 \%$ to $2.4 \%$ under anhydrous and hydrous crystallization conditions, respectively (Table 3 and Fig.4c). At 0.5 and $1 \mathrm{~h}$, the amount (0.5-0.8\%) of crystals from anhydrous experiments is apparently lower than that (1.4-1.8\%) measured in the hydrous ones, despite area fraction estimates are affected by great uncertainties (Fig.4c). Moreover, no clear trends are observed with increasing dwell time (Fig.4c). The titanomagnetite morphology is well-developed with most of the crystals showing euhedral shapes and only rare subhedral (hollow-to-hopper) textures. Highly dendritic morphologies, as those obtained in fast (up to $15^{\circ} \mathrm{C} / \mathrm{min}$ ) cooling rate experiments (Hammer, 2006; Mollo et al., 2013b) are never observed. The mean maximum crystal size varies from $5 \mu \mathrm{m}(0.5 \mathrm{~h})$ to $11 \mu \mathrm{m}(24 \mathrm{~h})$ and from $7 \mu \mathrm{m}(0.5 \mathrm{~h})$ to $23 \mu \mathrm{m}(24 \mathrm{~h})$ under anhydrous and hydrous conditions, respectively (Fig. 4d). These data are comparable with $d$ values calculated through the batch method, and similar trends are also found for $L_{d}$ from CSD analysis (Table 3). The morphological evolution of titanomagnetite cannot be accurately quantified through the $S_{v}^{P}$ parameter due to the extremely low crystal content and volumetric density of crystals, providing standard deviations close to the measured $S_{v}^{P}$ values. The CSD curves derived for the experimental titanomagnetite grains are showed in Fig. 6 where the natural logarithm of the population density is plotted against the crystal size. As a general rule, larger crystal bins develop with increasing dwell time. The plots exhibit also a gentle downturn at small crystal sizes that, sometimes, is accompanied by a weak upward convexity, more pronounced for crystal populations from $24 \mathrm{~h}$ experiments. CSDs from anhydrous time-series are characterized by shallower slopes than those from hydrous experiments. The anhydrous CSD curves display comparable shapes, with lower slopes and intercepts at longer dwell times (Table 3). The hydrous CSD curves are also very similar in terms of crystal populations and shapes, with a subtler decrease in slope and intercept when the dwell time increases from 0.5 to $8 \mathrm{~h}$ (Table 3). At $24 \mathrm{~h}$, the crystal population skews significantly towards larger crystal size bins, thus defining a much smoother shape of the CSD (Fig. 6 and Table 3). This abrupt deviation is also related to the textural change of clinopyroxene observed at the same dwell time (see discussion below).

\subsubsection{Crystal growth kinetics}


The value of $G_{\max }$ measured for clinopyroxene ranges from $4.98 \times 10^{-8}$ to $1.49 \times 10^{-6} \mathrm{~cm} / \mathrm{s}$ and from $6.94 \times 10^{-8}$ to $1.80 \times 10^{-6} \mathrm{~cm} / \mathrm{s}$ under anhydrous and hydrous conditions, respectively (Table 2). The $\log G_{\max }$ vs. $\log t$ diagram shows that the growth rate decreases with increasing dwell time (Fig. 7). Data from anhydrous and hydrous isothermal time-series overlap within their uncertainties (Table 2 and Fig. 7), with the only exception observed for $24 \mathrm{~h}$ charges where the hydrous $G_{m a x}$ is sensibly higher than the anhydrous counterpart. The linear regression fit of the data yields the following equations:

$$
\begin{aligned}
& \text { anhydrous } \log G_{\max }=-0.894 \log t-2.906\left(R^{2}=0.99\right) \\
& \text { hydrous } \log G_{\max }=-0.851 \log t-3.029\left(R^{2}=0.99\right)
\end{aligned}
$$

The regressed data show an excellent linearity between $\log G_{\max }$ and $\log t$ (Fig. 7), with a high correlation coefficient $\left(R^{2}=0.99\right)$. The regression fits are characterized by positive intercepts and negative slopes that, however, do not perfectly overlap due to the different $G_{\max }$ values measured at $24 \mathrm{~h}$. The slope of the log-log linear trend has been proposed to give insights into the rate-limiting process for the crystal growth (i.e., interface- vs. diffusion-limited crystallization regimes; Burkhard, 2005; Orlando et al., 2008), whereas the intercept represents the logarithm of growth rate extrapolated at the time zero.

The growth rates of titanomagnetite crystals have been determined through the three methods described above and listed in Table 3. As the dwell time increases, $G_{\max }$ (Method 1) decreases from $1.48 \times 10^{-7}$ to $6.62 \times 10^{-9} \mathrm{~cm} / \mathrm{s}$ and from $2.00 \times 10^{-7}$ to $1.34 \times 10^{-8} \mathrm{~cm} / \mathrm{s}$ under anhydrous and hydrous conditions, respectively. The batch growth rate (Method 2) provides values that are one order of magnitude lower than $G_{\max }$ and ranging from $3.52 \times 10^{-8}$ to $1.44 \times 10^{-9}$ (anhydrous data) and from $4.64 \times 10^{-8}$ to $4.04 \times 10^{-9}$ (hydrous data). Similar estimates have been also derived through the CSD analysis (Method 3). As for the case of clinopyroxene, titanomagnetite crystals with higher growth rates formed over shorter dwell times (Table 3). The $\log G_{\max }$ vs. $\log t$ diagram exhibits similar linear trends for both anhydrous and hydrous time-series experiments (Fig. 8) that are described by the following equations:

$$
\begin{aligned}
& \text { anhydrous } \log G_{\text {max }}=-0.787 \log t-4.261\left(R^{2}=0.99\right) \\
& \text { anhydrous } \log G_{\text {batch }}=-0.843 \log t-4.683\left(R^{2}=0.99\right) \\
& \text { anhydrous } \log G_{C S D}=-0.783 \log t-4.927\left(R^{2}=0.98\right)
\end{aligned}
$$




$$
\begin{aligned}
& \text { hydrous } \log G_{\max }=-0.731 \log t-4.360\left(R^{2}=0.98\right) \\
& \text { hydrous } \log G_{\text {batch }}=-0.687 \log t-5.190\left(R^{2}=0.91\right) \\
& \text { hydrous } \log G_{C S D}=-0.610 \log t-5.519\left(R^{2}=0.91\right)
\end{aligned}
$$

The regression fits of growth rates calculated through Method 2 and Method 3 show comparable intercepts and slopes, attesting the reliability of estimates. Hydrous experiments show slight slop variations as a function of the different growth rates estimated for the $24 \mathrm{~h}$ experiment (Fig. 8).

\subsection{Mineral and melt chemistry}

Clinopyroxenes from anhydrous ( $\left.\mathrm{Wo}_{43-46}-\mathrm{En}_{37-40}-\mathrm{Fs}_{16-19}\right)$ and hydrous $\left(\mathrm{Wo}_{44-47}-\mathrm{En}_{37-41}-\mathrm{Fs}_{15}\right.$ 17) experiments are classified as diopside-augite (Table 1S) according to the classification scheme of Morimoto (1988). With respect to the anhydrous charges, the compositions of crystals obtained under hydrous conditions show higher values of $\mathrm{Si}$, Mg-number $\left[\mathrm{Mg} \#=100 \times \mathrm{Mg} /\left(\mathrm{Mg}+\mathrm{Fe}_{\text {tot }}\right)\right.$ on molar basis] and diopside + hedenbergite $(\mathrm{DiHd})$, and lower values of tetrahedrally-coordinated aluminum $\left({ }^{\mathrm{T}} \mathrm{Al}\right), \mathrm{Fe}^{3+}$, enstatite + ferrosilite $(\mathrm{EnFs})$ and $\mathrm{Ca}-\mathrm{Tschermak}+\mathrm{CaTi}$-Tschermak $+\mathrm{CaFe}-$ Tschermak $(\mathrm{CaTs}+\mathrm{CaTiTs}+\mathrm{CaFeTs}=\mathrm{Ts})($ Fig. 9). The mineral chemistry also changes as a function of dwell time. ${ }^{\mathrm{T}} \mathrm{Al}$ and $\mathrm{Fe}^{3+}$ are preferentially incorporated in clinopyroxenes from $0.5-2 \mathrm{~h}$ experiments, whereas Si content increases in crystals from 4 to $24 \mathrm{~h}$ charges (Fig. 9). No clear trends are observed for Ti but, from a statistical point of view, its concentration slightly decreases with dwell time, as documented for ${ }^{\mathrm{T}} \mathrm{Al}$ and $\mathrm{Fe}^{3+}$. Overall, clinopyroxene crystals are progressively enriched in DiHd and depleted in Ts from 4 to $24 \mathrm{~h}$ charges (Fig. 9). The compositional change is determined by the kinetically-controlled cation exchange $(\mathrm{Si}+\mathrm{Mg}) \rightarrow\left({ }^{\mathrm{T}} \mathrm{Al}+\mathrm{Fe}^{3+}\right)$, expanding the Ts stability at the expense of Di over short time durations. Additionally, for each single experiment, strong crystal zoning is recognized either for large euhedral clinopyroxenes or dendritic crystals with analyzable cores and rims. Fig. 10a shows Di-poor and Di-rich clinopyroxene portions in which mineral compositional changes have been evidenced using a high contrast in backscattered electron images highlighting Fe-Mg crystal zoning. Fig. 10b displays also an example of electron microprobe profile analyzed across the crystal and the surrounding glass. A traverse of 5 - $\mu \mathrm{m}$-step has been performed for $\mathrm{SiO}_{2}, \mathrm{MgO}, \mathrm{Al}_{2} \mathrm{O}_{3}$, and $\mathrm{FeO}$. By assuming $\mathrm{SiO}_{2}$ and $\mathrm{MgO}$ variations as a proxy for Di component in clinopyroxene (Fig. 10b), the crystal zoning is characterized by Di-poor 
(Di43-44) and Di-rich ( $\left.\mathrm{Di}_{46-48}\right)$ compositions. It is apparent that complex zoning patterns develop by the overgrowth of Di-rich and well-faced crystals onto early-formed Di-poor dendrites (Fig. 10a-b).

Titanomagnetite exhibits an almost constant composition in all the experimental charges (Table 2S), showing $\mathrm{Al}_{2} \mathrm{O}_{3}$ (8.9-10.1 wt.\%) and $\mathrm{MgO}$ (5.4-5.8 wt.\%) enrichments typically observed under rapid crystal growth conditions (Mollo et al., 2013b). On the other hand, the amount of $\mathrm{TiO}_{2}$ (3.8-4.2 wt.\%) is relatively low, translating to an ulvospinel (Usp) content almost close to 1 mol.\% (Table 2S). Overall, the Ti-Al-Mg cationic substitutions in titanomagnetite indicate kinetic effects where $\mathrm{Al}+\mathrm{Mg}$ are more easily incorporated into disequilibrium crystals by lowering the number of Ti cations (Mollo et al., 2013b).

The residual glass composition (Table $3 \mathrm{~S}$ ) shifts from trachyandesite to basaltic trachyandesite (54.1-56.1 wt.\% $\mathrm{SiO}_{2}, 6.4-8.1$ wt.\% $\mathrm{Na}_{2} \mathrm{O}+\mathrm{K}_{2} \mathrm{O}$ and $\mathrm{Mg} \#_{50-54}$ ) and from trachybasalt to tephrite (45.6-48.9 wt.\% $\mathrm{SiO}_{2}, 6.2-7.8$ wt.\% $\mathrm{Na}_{2} \mathrm{O}+\mathrm{K}_{2} \mathrm{O}$ and $\mathrm{Mg} \#_{50-54}$ ) under anhydrous and hydrous crystallization conditions, respectively (data on anhydrous basis according to Le Bas et al., 1986). No clear glass compositional trends are found as a function of dwell time in both anhydrous and hydrous charges. The interstitial glass develops within a complex crystal framework causing marked compositional heterogeneity. This applies frequently in short dwell time experiments, where small glass pockets are isolated by dense dendrite crystallization where the variable contents and compositions of crystals induce, locally, strong glass chemical changes. On the other hand, microprobe chemical profiles performed in more abundant glass portions surrounding large and isolated crystals do not show concentration gradients next to the clinopyroxene surface (i.e., up to $30 \mu \mathrm{m}$ far from the crystal-glass interface; Fig. 10a-b).

\section{Discussion}

\subsection{Textural maturation of clinopyroxene}

Under both anhydrous and hydrous conditions, the experimental charges obtained at $0.5,2$, 4 , and $8 \mathrm{~h}$ are characterized by small clinopyroxenes with dendritic habits, whereas large and euhedral crystals develop at $24 \mathrm{~h}$. Due to the strong kinetic effects at the onset of crystallization, the maximum size ( $65 \mu \mathrm{m}$ on average) of clinopyroxene does not substantially change as the dwell time increases from 0.5 to $8 \mathrm{~h}$, whereas longer crystal lengths (100 $\mu \mathrm{m}$ on average) are measured at $24 \mathrm{~h}$ (Table 2). Within the time interval of 0.5-8 h, the size, content and growth rate of clinopyroxene do not differ significantly nor systematically between hydrous and anhydrous time-series experiments, suggesting the lack of complete equilibrium. Following the theory of nucleation proposed by the pioneer study of Kirkpatrick (1983), the activation energy required for the onset of nucleation is 
proportional to the number of tetrahedral units expressed as either Al-O bonds or the most energetic $\mathrm{Si}-\mathrm{O}$ bonds in the crystallizing silicate melt. A great number of tetrahedral units and corner connections implies a high nucleation barrier, which in turn determines high incubation times (Kirkpatrick, 1983). The clinopyroxene crystal structure comprises a few tetrahedral units, so that a relatively low number of structural re-arrangement is expected in the melt, translating to a short nucleation delay and the attainment of high area fractions (Fig. 4a). The occurrence of dendrites is addressed to melt supersaturation (e.g. Lofgren, 1974; Sunagawa, 1981) due to imposition of a thermodynamic driving force promoting early crystal nucleation rather than growth (e.g. Hammer, 2006, 2008). Figs. 2 and 3 highlight that, upon the effect of a large degree of initial undercooling, clinopyroxene dendrites from $0.5-8 \mathrm{~h}$ experiments are composed of tiny crystallites aligning along branches that are perpendicular to each other (i.e., different orders of branch generations; Faure et al., 2003). When the experimental charge is maintained isothermally for $24 \mathrm{~h}$, dendrite branches change into the prismatic and well-faced morphologies. The annealing treatment of $24 \mathrm{~h}$ before quench causes melt relaxation (i.e., equilibration) phenomena that are more effective with respect to the shorter dwell times (Dingwell \& Webb, 1990; McMillan and Wolf, 1995; Moynihan, 1995; Webb and Dingwell, 1995). Coherently, the growth of dendrites is less favored in more relaxed melt regions characterized by lower degrees of melt supersaturation (i.e., "Berg effect"; Berg, 1938). The lack of dendritic shapes in $24 \mathrm{~h}$ experiments (Fig. 3) points to a textural maturation of clinopyroxene documented typically under equilibrium conditions when crystallization takes place from a fully relaxed melt (Baker, 2008; Mollo et al., 2011, 2013c) or, alternatively, under extremely low degrees of undercooling when the growth rate largely exceeds the nucleation rate (Simakin et al., 2003; Orlando et al., 2008). Rationally, after the early effect of undercooling, the diffusionlimited growth of dendrites occurring at shorter dwell times (i.e., more effective melt saturation), translates to a steady-state regime under which euhedral crystals more favorably develop by interface-limited growth at longer dwell times (i.e., more effective melt relaxation; Figs. 2 and 3 ).

Well-faced morphologies in natural magmatic products, as those attained in porphyritic intrusions, are classically addressed to a high-temperature coarsening process of the small crystal populations over time (e.g., Park and Hanson, 1999; Higgins, 1998, 1999, 2011). In crystallization experiments conducted on analogue materials, Means and Park (1994) observed the evolution from dendritic to blocky crystal habits as related to segmentation of the dendrite branches and further coarsening of the resulting tiny crystals. A similar effect could be potentially applied to the decreasing area fraction of clinopyroxene observed for anhydrous experiments (Fig. 4a). However, due to the presence of scattered data affected by large uncertainties (up to $\pm 12.4 \%$ on average; see Table 2), no clear trends can be delineated for both anhydrous and hydrous time-series experiments 
(Fig. 4a). Alternatively, crystal growth mechanisms by dendrite attachment have been documented by both ex-situ (Pupier et al., 2008) and in-situ (Schiavi et al., 2009) laboratory observations conducted on basaltic melts. More specifically, these experiments reveal that the growth histories of individual crystals may proceed by intervals of relatively uniform free growth, abrupt size increase by grain coalescence, and growth reduction by impingement (Schiavi et al., 2009). Coalescence takes place when adjacent tiny crystals of similar orientation attach to form one (crystallographically) single crystal (Pupier et al., 2008). Additionally, coalescence phenomena can take place between crystals that are initially misaligned, thus involving further grain rotation (Schiavi et al., 2009). As the crystal fraction increases substantially, crystal impingement and overgrowth become the most important textural maturation mechanisms (Schiavi et al., 2009). Further experimental studies have demonstrated that attachment of tiny dendritic crystals can effectively lead to the formation of large homogeneous clinopyroxenes and plagioclases (Iezzi et al., 2011, 2014; Vetere et al., 2013, 2015). This is in agreement with the theory of aggregation by self-orientation of sub-micrometric crystals along crystallographic directions, in order to attain minimization of interfacial energies (Kostov and Kostov, 1999; Alivisatos, 2000; Banfield et al., 2000; Deer et al., 2001; Niederberger and Colfen, 2006; Sear, 2012; Teng, 2013). A similar attachment feature has been observed for the formation of large plagioclase crystals due to volatile exsolution and degassing of a fluid-saturated magma rising from depth (Crabtree and Lange, 2011; Frey and Lange, 2011). During flowage onto the surface, naturally cooling Hawaiian and Etnean lava flows may be characterized by massive crystallization (up to $\sim 60$ vol.\%) of microphenocrysts and microlites. In this context, the crystal growth is driven by attachments of clinopyroxene and plagioclase phenocrysts with lengths up to $1 \mathrm{~mm}$, having also important implications for the rheological behavior of lava flows (Crisp and Baloga, 1990; Crisp et al., 1994; Cashman et al., 1999; Soule et al., 2004; Lanzafame et al., 2013; Mollo et al., 2015). In naturally undercooled olivines, zoning patterns reveal a crystallization history marked by early diffusion-limited growth of interconnected branches forming a skeletal framework (Welsh et al., 2014; Shea et al., 2015). When undercooling decreases after the fast growth stage, the skeletal branches are partially infilled to yield well-faceted polyhedral crystals, as growth becomes interface-limited (Shea et al., 2015). Turning to the textural maturation of clinopyroxenes from this study (Figs. 2 and 3), it cannot be excluded that infilling of the early dendrite frameworks attaching to form a larger crystal takes place with the annealing time. Dendritic clinopyroxene crystals may represent an early diffusionlimited morphology caused by the large degree of initial undercooling and partly preserved by short annealing treatments. The melt is readily supersaturated in the slow-diffusing Al cations favoring the early growth of Di-poor dendrites (Fig. 10a-b) by the kinetically-controlled exchange $(\mathrm{Si}+\mathrm{Mg})$ 
$\rightarrow\left({ }^{\mathrm{T}} \mathrm{Al}+\mathrm{Fe}^{3+}\right)$ (Mollo et al., 2010; 2012a; 2013a). Subsequently, Di-rich overgrowths develop from the residual melt that becomes substantially enriched in $\mathrm{SiO}_{2}$ and $\mathrm{MgO}$ components (Fig. 10b). Melt relaxation and crystal attachment start to be effective phenomena when the temperature is maintained isothermally and, at this condition, the interface-controlled regime becomes more effective. As a consequence, early-formed Di-poor skeletal branches are partially infilled by the $\mathrm{SiO}_{2}$-MgO-rich melt, leading to the formation of Di-rich overgrowths (Fig. 10a-b). The transition between diffusion-limited to interface-limited morphologies through attachment and infilling of early dendrite branches may also explain the lack of a clear trend between clinopyroxene area fraction and dwell time (Fig. 4a), especially in hydrous experiments where the cation diffusivity in the melt is enhanced (Zhang et al., 2010).

The $S_{v}^{P}$ parameter of clinopyroxene progressively decreases with increasing dwell time (Table 2 and Fig. 5), evidencing that more euhedral morphologies are attained at $24 \mathrm{~h}$ by the textural maturation of the dendritic crystal habits. This corroborates the observation of Hammer $(2006,2009)$ that $S_{v}^{P}$ can be effectively used to quantify the degree of crystal euhedrality. From an energetic point of view, $S_{v}^{P}$ is directly proportional to the free energy change during melt solidification and represents part of the crystallization free energy term related to the development of crystal-melt interfaces (Hammer, 2006). Hence, the decreasing trend showed in Fig. 5 is an expression of the minimization of the free energy as the grain boundaries approach to equilibrium with the surrounding melt. This is consistent with what observed in the $\log G$ vs. $\log t$ diagrams derived for clinopyroxene (Fig. 7) and titanomagnetite (Fig. 8). The slopes of the log-log linear trends exhibit almost comparable values of $\sim 0.7-0.9$ that are invariably higher than the theoretical threshold of 0.5 derived under diffusion-limited crystal growth conditions (Müller-Krumbhaar, 1975; Burkhard, 2002, 2005; Orlando et al., 2008). On this basis, it can be inferred that the decrease of crystal growth with dwell time is mostly related to the progressive approach to (near-)equilibrium crystallization where attachment/detachment reactions of cations from the melt onto the crystalline surface (and vice versa) occur at the same rate. A similar interpretation has been given by Orlando et al. (2008), documenting that growth kinetics of plagioclase from trachybasaltic melts are generally faster than clinopyroxene, as the former exhibits steeper log-log linear trends with slopes close to 1 . According to Orlando et al. (2008), at $1170{ }^{\circ} \mathrm{C}$, plagioclase equilibrates with the melt in a shorter time interval of $3 \mathrm{~h}$, whereas clinopyroxene requires a longer time of $20 \mathrm{~h}$ that, importantly, is similar to the longest dwell time used in this study.

The values of $G_{\max }$ reported in Table 2 are highly comparable with those measured by previous authors for clinopyroxenes growing from similar basaltic and trachybasaltic melts. For hydrous hawaiitic melts, Simakin et al. (2003) measured $G_{\max }$ from $1.85 \times 10^{-5}$ to $2 \times 10^{-6} \mathrm{~cm} / \mathrm{s}$ 
when cooling rate experiments were quenched after $0.5 \mathrm{~h}$. Such data are in agreement with the high growth rates determined at the shortest dwell time adopted for the time-series experiments. Conversely, the low growth rates attained at $24 \mathrm{~h}$ match with those derived in the fast cooling rate experiments of Burkhard (2002) conducted on Hawaiian basalts. The in-situ observations performed by $\mathrm{Ni}$ et al. (2014) confirm that, after $\sim 1.5 \mathrm{~h}$, the growth rate of clinopyroxene is comprised between $1.7 \times 10^{-6}$ and $6 \times 10^{-7} \mathrm{~cm} / \mathrm{s}$, resembling values from $0.5-8 \mathrm{~h}$ time-series experiments. Remarkably, data from Baker (2008) are very close to results from this study, as the author adopted a comparable undercooling condition $\left(\Delta T=75^{\circ} \mathrm{C}\right)$ and a similar trachybasaltic melt from Mt. Etna volcano. For clinopyroxenes with dendritic, skeletal and swallowtail textures, Baker (2008) estimated growth rates comprised between $5.4 \times 10^{-7}$ and $9.4 \times 10^{-8} \mathrm{~cm} / \mathrm{s}$ for dwell times between 3.5 and $14 \mathrm{~h}$. In comparison with natural studies, CSD analyses performed by Oze and Winter (2005) on natural basalts yield clinopyroxene growth rates variable from $3.74 \times 10^{-6}$ to $1.00 \times 10^{-8}$ $\mathrm{cm} / \mathrm{s}$ over crystal residence times of $\sim 0.04-9 \mathrm{~h}$ (Table 2). In contrast, the static experiments of Burkhard (2005) on re-heated anhydrous basaltic glasses (dwell times of 22-576 h at 930-990 ${ }^{\circ} \mathrm{C}$ and $1 \mathrm{~atm})$, and the low undercooling $\left(\Delta T=20^{\circ} \mathrm{C}\right)$ experiments of Orlando et al (2008) on seeded anhydrous trachybasalts (dwell times of $3-40 \mathrm{~h}$ at $1170{ }^{\circ} \mathrm{C}$ and $1 \mathrm{~atm}$ ), resulted in growth rates up to one order of magnitude lower than those from this study (Fig. 11). According to a great number of authors (e.g. Dowty, 1980; Lofgren \& Russell, 1986; Lesher et al., 1999; Conte et al., 2006; Mollo et al., 2013b), rapid crystallization kinetics are usually attained in experiments employing high degrees of undercooling or cooling rate. The lower slopes of log-log trends from Orlando et al. (2008) stands for the smaller degrees of undercooling used to approach equilibrium crystal sizes with respect to dendrites developed during time-series experiments (Fig. 11). This reflects distinct crystallization mechanisms operating at different degrees of undercooling (e.g. Kirkpatrick, 1975; Sunagawa, 2005; Faure et al., 2007; Ni et al., 2014). Indeed, at low degrees of undercooling, the textural maturation proceeds through screw dislocation and layer-by-layer growth determining smooth growth surfaces and euhedral morphologies, while at higher degrees of undercooling crystal nucleation dominates resulting in dendritic and skeletal morphologies. Log-log trends from the experiments of Burkhard (2005) show an overall slope of $\sim 1$ (Fig. 11), confirming the achievement of equilibrium crystal sizes for clinopyroxenes annealed over 20-24 h.

\subsection{Textural maturation of titanomagnetite}

Titanomagnetite crystals have strong tendency to attain euhedral habits at the shortest dwell time of $0.5 \mathrm{~h}$ (Table 3). The extremely fast textural maturation documented in this study can be addressed to the high interfacial energies occurring between oxide crystals and silicate melts 
(Hammer, 2006). This effect is enhanced by the application of an isothermal temperature after rapid cooling rate conditions, as demonstrated by Mollo et al. (2012a) who compared two sets of identical cooling rate experiments, the first immediately quenched after cooling and the second kept at the final temperature over a certain time. It is also important to note that small titanomagnetites nucleate, sometimes, on the tip of branches formed by clinopyroxene dendrites (Fig. 3). According to cooling rate experiments conducted on basaltic melts by Hammer et al. (2010), there is a preferential epitaxial relationship between the $\{110\}_{\text {timt }}$ and $\{010\}_{\mathrm{cpx}}$ faces, resulting from heterogeneous nucleation of tiny titanomagnetite crystals on dendrite branches of clinopyroxene. Moreover, compositional gradients arising during dendrite growth may provide a further thermodynamic driving force for heterogeneous nucleation of chemically different phases (Kirkpatrick, 1975; Walker et al., 1976; Hammer, 2006; Mollo et al., 2012b). This textural relationship becomes less frequent with increasing dwell time, especially when the textural maturation produces larger and euhedral clinopyroxene crystals (Fig. 3). Energetically unfavorable grain boundaries develop as the growth rate prevails over the nucleation rate, causing an increase in the surface energy associated with the crystal-crystal interface relative to the crystal-melt one (Hammer et al., 2010). The maximum size (10 $\mu \mathrm{m}$ on average) of titanomagnetite slightly changes from 0.5 to $8 \mathrm{~h}$, but then increases significantly ( $23 \mu \mathrm{m}$ on average) in hydrous experiments equilibrated for $24 \mathrm{~h}$ (Table 3). The titanomagnetite growth rates $\left(G_{\max }>G_{\text {batch }} \approx G_{C S D}\right)$ invariably decrease with increasing dwell time (Table 3 and Fig. 8). This relationship is confirmed by the intercept values of $\log -\log$ trends, representing growth rates extrapolated at the time zero. The value of $G_{\max }$ is up to five times higher than those of $\mathrm{G}_{\mathrm{CSD}}$ and $\mathrm{G}_{\mathrm{batch}}$, resembling data (from $1.2 \times 10^{-8}$ to $\left.3.5 \times 10^{-9} \mathrm{~cm} / \mathrm{s}\right)$ obtained from the heating experiments of Burkhardt $(2002,2005)$. With respect to natural titanomagnetites studied by Oze and Winter (2005), the growth rates from CSD analysis of time-series experiments largely overlap those estimated from phenocryst populations modelled at residence times of 0.12-6 h.

Log-log linear trends for titanomagnetite show slopes shallower than those derived for clinopyroxene (see Eq.12a-c and Eq.13a-c; Figs. 7 and 8), indicating prolonged growth of the former crystal phase (Orlando et al., 2008). This is also evidenced by the counterclockwise rotation of the CSD curves as a function of time (Fig. 6). Although the CSD analysis of experimental products cannot be directly matched to that of natural rocks, the evolution of scale invariant parameters (such as the slope) allows to evaluate the interplay between nucleation and growth mechanisms. The fan-like evolution of CSDs is typically observed in natural and experimental igneous systems (e.g. Waters \& Boudreau, 1996; Marsh, 1998; Pupier et al., 2008; Schiavi et al., 2009), in which an increased importance of growth vs. nucleation reflects the progressive evolution 
of the melt composition and the decreasing liquidus temperature with increasing crystal content (e.g. Cashman, 1993; Hammer, 2008). Generally, for equivalent dwell times, titanomagnetite CSD curves from hydrous experiments exhibit slopes slightly shallower than crystal populations from anhydrous charges. Under hydrous crystallization conditions and high degrees of undercooling, Muncill and Lasaga (1988) observed an increased crystal growth rate with respect to early anhydrous experiments (Muncill \& Lasaga, 1987), responding to crystallization kinetics enhanced by the effect of water on cation diffusivity in the melt (e.g., Dowty, 1980; Davis et al., 1997; Lasaga, 1998; Hammer, 2008; Calzolaio et al., 2010; Zhang, 2010). Nevertheless, at dwell times of $24 \mathrm{~h}$, a striking difference is observed in the titanomagnetite crystalline population, exhibiting skewness towards larger sizes and drastically shallower slopes (Fig. 6 and Table 3). In this respect, the attainment of euhedral textures for clinopyroxene crystals at the same dwell times may have influenced the textural development of titanomagnetite crystals, causing shift from heterogeneous nucleation to a growth-dominated crystallization regime. Intriguingly, a downturn of the CSD curve is observed in almost all the experiments at the smaller crystal size bins (Fig. 6). This effect has been previously interpreted as an inadequate spatial resolution of the analyzed images (Hammer et al., 1999; Higgins, 2006; Armienti, 2008), the evidence of textural coarsening (e.g., Higgins, 1998, 1999, 2011; Ni et al., 2014), or a decrease of the nucleation rate with decreasing the residual melt volume (Marsh, 1998). However, BSE microphotographs show a high resolution that, in most cases, is less than one micron. Moreover, the observed fan-like evolution of CSD curves cannot be accounted by the sole decrease of nucleation rate with time that, in turn, is mostly restricted to area fractions higher than 50\% in a closed system (Marsh, 1998). Indeed, the ex-situ cooling experiments of Pupier et al., (2008) and the in-situ textural observations conducted by Schiavi et al. (2009) attest that fanning evolution and the concave downward curve at the small grain size results from a decrease in the number of small grains in favor of large grains over time (i.e., Ostwald ripening and grain coalescence).

\subsection{Crystal growth vs. cation diffusivity in the melt}

One intriguing feature from time-series experiments presented in this study is the lack of clear concentration gradients in the glass surrounding the clinopyroxene crystals (Fig. 10a-b) that is apparently in contrast with the complex textures and compositions, as well as the overall increase in DiHd relative to Ts with increasing dwell time (Fig. 9). It is known that a high degree of undercooling favors a diffusion-limited crystallization regime accompanied by the development of a diffusive boundary layer in the melt next to the growing crystal face (Dowty, 1980; Lofgren and Smith, 1980; Kirkpatrick, 1981; Hammer, 2008; Mollo and Hammer, 2017). The deviation from 
homogeneous equilibrium increases, as the crystal growth rate greatly exceeds the diffusion rates of chemical species in the melt (Kirkpatrick, 1981). Compositional gradients develop in the melt feeding the crystal growth, so that cations compatible with the crystal lattice are depleted in the melt near the crystal surface, whereas the incompatible cations are rejected from the advancing crystal surface and enriched in the adjacent melt (Kirkpatrick, 1981). Mollo et al. (2013a, 2013c) conducted cooling rate experiments on the same trachybasaltic melt used in this study, with the difference that the charges were immediately quenched at the end of cooling and no dwell times or annealing times were applied before quenching. The authors observed that the composition of clinopyroxene is sympathetic with the enrichment or depletion of cations in the diffusive boundary layer supplying nutrients to the advancing crystal surface, responding to the cation exchange ( $\mathrm{Si}+$ $\mathrm{Mg}) \rightarrow\left({ }^{\mathrm{T}} \mathrm{Al}+\mathrm{Fe}^{3+}\right)$. It is worth stressing that the thickness of the diffusive boundary layer at the crystal-melt interface decreases with dwell time, as the chemical species are more efficiently rejected away from the crystal surface (Dowty, 1980; Lofgren and Smith, 1980). The melt becomes fully relaxed and all chemical gradients cease when the diffusing chemical components have sufficient time to re-equilibrate with the original bulk composition of the far-field melt (Kirkpatrick, 1981; Baker, 2008). Disequilibrium cation partitioning during rapid crystal growth may also takes place in presence of a very thin diffusive boundary layer around the growing crystals (Watson and Muller, 2009). This is especially true for low viscosity melts, such as trachybasalts at Mt. Etna volcano, so that the thin diffusive boundary layer is limited to the region affected by cation interactions with the crystal surface (Watson and Muller, 2009). According to the experiments of Baker (2008), after initial undercooling, the clinopyroxene growth rate significantly decreases with time, causing the concentration gradients in the melt adjacent to the crystal surface to decrease by diffusive relaxation. The same applies to melt inclusions where their entrapment require interfacelimited phenomena where an early rapid crystal growth forms melt embayments. Subsequently, a period of slow growth is necessary to seal and isolate the embayment during interface-limited textural maturation (e.g., Stewart and Pearce 2004; Blundy and Cashman 2005). Data from this study confirm that $G_{\max }$ decreases by one order of magnitude with dwell time from 0.5 to 24 hours, favoring the shift from a diffusion-limited to an interface-limited crystallization regime (Fig. 7). Therefore, the lack of an analyzable diffusive boundary layer next to the crystal surface may be addressed to 1) the decreasing crystal growth rate with dwell time 2) the fast diffusivity of cations in the trachybasaltic melt and 3) the development of a thin diffusive boundary layer close to the spatial resolution limits of the microprobe. The diffusion coefficients $(D)$ of cations compatible $(\mathrm{Mg}$ and $\mathrm{Ca}$ ) and incompatible ( $\mathrm{Al}$ and $\mathrm{Na}$ ) with clinopyroxene crystal lattice have been calculated through the equations $23\left(D_{M g}=5-6 \times 10^{-13} \mathrm{~m}^{2} / \mathrm{s}\right), 24\left(D_{C a}=6-7 \times 10^{-12} \mathrm{~m}^{2} / \mathrm{s}\right)$ and $36\left(D_{A l}=8-9 \times\right.$ 
$67610^{-14} \mathrm{~m}^{2} / \mathrm{s}$ ) reported in the review study of Zhang et al. (2010), as well as through equation SEBD ${ }_{6}^{1} 77\left(D_{N a}=7-8 \times 10^{-10} \mathrm{~m}^{2} / \mathrm{s}\right)$ reported in Chen and Zhang (2009). Note that these equations were derived 638 by the regression fit of anhydrous experimental data, consequently, the calculated diffusion coefficients represent a conservative limit for the cation mobility in the melt that, in turn, is enhanced by the effect of $\mathrm{H}_{2} \mathrm{O}$. The isothermal temperature of $1,100{ }^{\circ} \mathrm{C}$ was used as input data for calculations, together with the average analyses of glasses from experimental charges, representing the quenched melt feeding the clinopyroxene growth. Assuming absence of convection fluxes in the experimental capsules, the cation diffusion length $d$ was derived as follows (Baker, 2008):

$$
d=\sqrt{D t}
$$

In the $\log -\log$ diagram presented in Fig. 12a, the diffusion length $(\log d)$ is plotted against the experimental dwell time $(\log t)$. During clinopyroxene growth by dendrite attachment, the size of single and isolated dendrites varies from $\sim 5$ to $\sim 50 \mu \mathrm{m}$ under both anhydrous and hydrous conditions. This range is comparable with the logd calculated for $\mathrm{Al}$ and $\mathrm{Mg}$ at 0.5 and $1 \mathrm{~h}$ (Fig. 12a). In contrast, at $24 \mathrm{~h}$, the dendrite size is always lower than $d$, suggesting that the diffusivity in the melt is fast enough to supply fresh cations from the far-field (relaxed) melt to the advancing crystal surface (Fig. 12a). Moreover, from 0.5 to $24 \mathrm{~h}$ dwell times, all the dendrites with size lower than $12 \mu \mathrm{m}$ do never intercept the travelling distance of $\mathrm{Al}$ (i.e., the slow-diffusing incompatible cation). Evidently, when the experimental charges were cooled from the superliquidus condition down to the isothermal temperature of $1,100{ }^{\circ} \mathrm{C}$, the melt was rapidly supersaturated in $\mathrm{Al}$ by the fast nucleation and growth of Di-poor dendrites. However, the diffusive boundary layer developing at the dendrite-melt interface was extremely thin, so that the system readily shifted from diffusionlimited to interface-limited conditions, favoring the overgrowth of Di-rich crystals. To test this hypothesis, the 1-dimensional "disequilibrium" crystal growth equation derived by Watson and Muller (2009) has been used to model how the early enrichment of Al in clinopyroxene dendrites is controlled by the thickness of the diffusive boundary layer in the melt. Importantly, Al is ratelimiting for the disequilibrium growth of clinopyroxene due to its slow diffusivity in the melt phase (cf. Iezzi et al., 2011, 2014; Mollo et al., 2013a, 2013c). Moreover, Al is incompatible with clinopyroxene crystal lattice and its concentration increases in the diffusive boundary layer as the crystal growth rate increases. Data from this study show that the partition coefficient $\left(K_{A l}\right)$ of $\mathrm{Al}$ measured at the clinopyroxene-glass interface decreases from 0.77 to 0.45 with increasing dwell time. According to the kinetically-controlled cation exchange $(\mathrm{Si}+\mathrm{Mg}) \rightarrow\left({ }^{\mathrm{T}} \mathrm{Al}+\mathrm{Fe}^{3+}\right)$, the concentration of ${ }^{\mathrm{T}} \mathrm{A} 1$ in clinopyroxene decreases from $\sim 0.43$ apfu for the disequilibrium (Di-poor) 
dendrites to $\sim 0.21$ apfu for the near-equilibrium (Di-rich) overgrowths (Fig. 9). The disequilibrium incorporation of $\mathrm{Al}$ in rapidly growing dendrites can be modelled through the following expression (Watson and Muller, 2009):

$$
\text { Disequilibrium } \mathrm{Al}_{2} \mathrm{O}_{3} \text { in dendrites }=\frac{\text { Equilibrium } \mathrm{Al}_{2} \mathrm{O}_{3} \text { in overgrowths }}{1-\left(1-K_{A l}\right) \frac{G_{\max }}{D_{A l}} d}
$$

Considering that melt supersaturation phenomena refer mostly to the fast growth rate (1.49-1.80 $x$ $10^{-6} \mathrm{~cm} / \mathrm{s}$; Table 2) of clinopyroxene, the thickness of the diffusive boundary layer controlling the disequilibrium uptake of $\mathrm{Al}$ in early-formed dendrites varied from $\sim 1$ to $\sim 2 \mu \mathrm{m}$ as a function of $K_{A l}$ (Fig. 12b). Therefore, the boundary layer enriched in slow-diffusing incompatible cations and feeding the growth of tiny Di-poor dendrites may have rapidly disappeared after a relatively short time, being replaced by Di-rich overgrowths forming under near-equilibrium conditions.

\section{Conclusive remarks}

Textural and compositional data presented in this experimental study underline the importance of crystallization kinetics in the solidification of silicate melt. Due to the early effect of undercooling, the system attempts to approach a more thermodynamically convenient configuration of crystal-melt interfaces. Particularly, results from time-series experiments points towards a mineral textural evolution dominated by extremely fast crystal growth rates. Near-equilibrium crystal contents are also attained over relatively short dwell times of a few hours. The crystallization proceeds isothermally by minimizing the interfacial free energy between melt and crystal morphologies characterized by high surface to the volume ratio of tiny dendrites. The implications for volcanic systems are of first order relevance, especially when considering the development of porphyritic textures. For example, nearly constant temperatures may enhance the textural evolution of phenocrysts in magmas located at shallow-to-intermediate crustal depths where strong undercooling phenomena may take place. Overall, the most important outcomes from this study can be summarized as follows:

1) the textural evolution of clinopyroxene is dominated by progressive maturation of an early formed Di-poor, Al-rich dendritic fabric that, however, is characterized by a slightly changing area fraction ( $45 \%$ on average) from 0.5 to $24 \mathrm{~h}$;

2) the attachment of clinopyroxene skeletal branches is accompanied by infilling and overgrowth of Di-rich, Al-poor crystal portions due to the shift from a diffusion-limited to an interface-limited growth regime; 
3) the textural maturation by infilling and overgrowth agrees with the minimization of crystalmelt interfaces suggested by the decreasing value of $S_{v}^{P}$ with dwell time, as well as the lack of a clear increasing crystallinity;

4) the euhedral morphology of titanomagnetite immediately develop at the early stage of crystal nucleation and growth;

5) the CSD analysis of titanomagnetite crystals points to a textural evolution by coarsening;

6 ) in $0.5-8 \mathrm{~h}$ experiments, the early dendritic growth of clinopyroxene seems to facilitate the heterogeneous nucleation of titanomagnetite grains;

7) conversely, in $24 \mathrm{~h}$ experiments, the coarsening of titanomagnetite appears related to the achievement of a near-equilibrium morphology for the clinopyroxene.

\section{Figure captions}

Fig. 1. Explanatory illustration of the image segmentation procedure. Original BSE image showing clinopyroxene (Cpx), titanomagnetite (Timt) and glass (Gl) (a). Thresholding procedure conducted through the ImageJ code and binarization of the image identifying clinopyroxene (black), titanomagnetite (red) and glass (white). Cpx, clinopyroxene. Timt, titanomagnetite. Gl, glass.

Fig. 2. Textural development of clinopyroxene crystals from anhydrous and hydrous time-series experiments. Equal-area best-fit ellipses (with major and minor axes) are derived by the ImageJ code and superimposed on the segmented clinopyroxene crystals.

Fig. 3. Backscattered electron (BSE) images of experimental run products from anhydrous and hydrous time series. Cpx, clinopyroxene. Timt, titanomagnetite. Gl, glass

Fig. 4. Variations of clinopyroxene and titanomagnetite textural parameters with dwell time. Clinopyroxene area fraction (a) and maximum crystal size (b). Titanomagnetite area fraction (c) and maximum crystal size (d). Cpx, clinopyroxene. Timt, titanomagnetite.

Fig. 5. Variation of surface area to volume ratio $\left(S_{v}^{P}\right)$ parameter of clinopyroxene with dwell time for both anhydrous (red diamonds) and hydrous (blue diamonds) time-series experiments.

Fig. 6. Crystal Size Distribution (CSD) analysis of titanomagnetite for both anhydrous (red diamonds) and hydrous (blue diamonds) time-series experiments. 
Fig. 7. $\log G_{\max }$ vs. $\log t$ diagram based on clinopyroxene data from anhydrous and hydrous experiments.

Fig. 8. $\log G$ vs. $\log t$ diagram based on titanomagnetite data from anhydrous (a) and hydrous (b) experiments.

Fig. 9. Clinopyroxene compositional variation as a function of dwell time. $\mathrm{Mg} \#=100 \times \mathrm{Mg} /(\mathrm{Mg}+$ $\left.\mathrm{Fe}_{\text {tot }}\right)$ on molar basis. DiHd $=$ diopside $(\mathrm{Di})+$ hedenbergite $(\mathrm{Hd})$. EnFs $=$ enstatite $(\mathrm{En})+$ ferrosilite $(\mathrm{Fs}) . \mathrm{Ts}=\mathrm{Ca}-\mathrm{Tschermak}(\mathrm{CaTs})+\mathrm{CaTi}$-Tschermak $(\mathrm{CaTiTs})+\mathrm{CaFe}-\mathrm{Tschermak}(\mathrm{CaFeTs})$.

Fig. 10. Clinopyroxene Di-poor and Di-rich compositional variations revealed by backscattered electron (BSE) microphotographs (a). The high contrast used for the image highlights as Fe cations in clinopyroxene backscatter electrons better than $\mathrm{Mg}$ ones. Example of electron microprobe profile (i.e., 5- $\mu$ m-step traverses) for $\mathrm{SiO}_{2}, \mathrm{MgO}, \mathrm{Al}_{2} \mathrm{O}_{3}$, and $\mathrm{FeO}$ analyzed across the crystal and surrounding glass (b). The complex zoning pattern is characterized by overgrowth of Di-rich and well-faced crystals onto early-formed Di-poor dendrites.

Fig. 11. $\log G$ vs. $\log t$ diagram in which clinopyroxene data from this study are compared with those from the experimental studies of Orlando et al. (2008) and Burkhard (2005).

Fig. 12. Log-log diagram showing the diffusion length $(\log d)$ plotted against the experimental dwell time $(\log t)(\mathrm{a})$. The size of single and isolate dendrites is also reported for comparison as a grey area. Modelling data from the equation of Watson and Muller (2009) showing the control of the thickness $(d)$ of the diffusive boundary layer in the melt on the $\mathrm{Al}_{2} \mathrm{O}_{3}$ concentration of clinopyroxene (b).

\section{References}

Alivisatos, A.P., 2000. Naturally aligned nanocrystals. Science 289, 736-737

Armienti, P., Innocenti, F., Petrini, R., Pompilio, M. \& Villari, L., 1988. Subaphyric alkali basalt from Etna: Inferences on depth and composition of the source magma. Rend. Soc. Ital. Miner. Petrol. 43, 877-891. 
Armienti, P., Pareschi, M.T., Pompilio, M., Innocenti, F., 1994. Effects of magma storage and 8313 ascent on the kinetics of crystal growth: the case of the 1991-1993Mt. Etna eruption. Contrib. Mineral. Petrol. 115, 402-414.

Armienti, P., 2008. Decryption of igneous rock textures: crystal size distribution tools. In: Putirka, K. D. \& Tepley, F. J., III (eds) Minerals, Inclusions and Volcanic Processes. Rev. Mineral. Geochem. 69 , 623-649.

Armienti, P., Perinelli, C., Putirka, K.D., 2013. A new model to estimate deep-level magma ascent rates, with applications to Mt. Etna (Sicily, Italy). J. Petrol. 54, 795-813.

Baker, D.R., 2008. The fidelity of melt inclusions as records of melt composition. Contributions to Mineralogy and Petrology, 156, 377-395.

Banfield, J.F., Welch, S.A., Zhang, H., Ebert, T.T., Penn, R.L. (2000) Aggregation-based crystal growth and microstructure development in natural iron oxyhydroxide biomineralization products.

Science, $289,751-754$

Berg, W. F., 1938. Crystal growth from solutions. Proc. R. Soc. Lond. A, 164, 79-95.

Blundy, J., and Cashman, K., 2008. Petrologic reconstruction of magmatic system variables and processes. In K.D. Putirka and F.J. Tepley, Eds., Minerals, Inclusions and Volcanic Processes, 69, 179-239. Reviews in Mineralogy and Geochemistry, Mineralogical Society of America, Chantilly, Virginia.

Blundy, J. and Cashman, K., 2005. Rapid decompression-driven crystallization recorded by melt inclusions from Mount St. Helens volcano. Geology, 33, 793-796.

Brugger, C.R. and Hammer, J.E., 2010a. Crystal size distribution analysis of plagioclase in experimentally decompressed hydrous rhyodacite magma. Earth and Planetary Science Letters, $300,246-254$.

Brugger, C.R., Hammer, J.E., 2010b. Crystallization kinetics in continuous decompression 
experiments: implications for interpreting natural magma ascent processes. J. Petrol. 51, 1941-1965

Burkhard, D.J.M., 2002. Kinetics of crystallization: example of micro-crystallization in basalt lava. Contributions to Mineralogy and Petrology 142, 724-737.

Burkhard, D.J.M., 2005. Nucleation and growth rates of pyroxene, plagioclase, and Fe-Ti oxides in basalt under atmospheric conditions. Eur J. Mineral. 17, 675-685.

Cabane, H., Laporte, D., Provost, A., 2001. Experimental investigation of the kinetics of Ostwald ripening of quartz in silicic melts. Contrib Mineral Petrol 142:361-373

Cabane, H., Laporte, D. and Provost, A., 2005. An experimental study of Ostwald ripening of olivine and plagioclase in silicate melts: Implications for the growth and size of crystals in magmas. Contributions to Mineralogy and Petrology, 150, 37-53

Calzolaio, M., Arzilli, F., Carroll, M. R., 2010. Growth rate of alkali feldspars in ecompressioninduced crystallization experiments in a trachytic melt of the Phlegraean Fields (Napoli, Italy). European Journal of Mineralogy, 22, 485-493.

Cashman, K.V., 1990. Textural constraints on the kinetics of crystallization of igneous rocks. Rev Mineral. 24:259-314

Cashman, K.V., 1992. Groundmass crystallization of Mount St. Helens dacite, 1980-1986: A tool for interpreting shallow magmatic processes. Contrib Mineral Petrol 109:431-449

Cashman, K.V., 1993. Relationship between plagioclase crystallization and cooling rate in basaltic melts. Contrib. Mineral. Petrol. 113, 126-142.

Cashman, K.V., Marsh, B.D., 1988. Crystal size distribution (CSD) in rocks and the kinetics and dynamics of crystallization II: Makaopuhi lava lake. Contrib. Mineral. Petrol. 99, 292-305.

Cashman, K., Blundy, J., 2000. Degassing and crystallization of ascending andesite. Phil. Trans. Roy. Soc. 358, 1487-1513 
Cashman, K.V., Thornber, C., Kauahikaua, J.P., 1999. Cooling and crystallization of lava in open channels, and the transition of pahoehoe to aa. Bull. Volcanol. 61, 306-323.

Conte, A., Perinelli, C., Trigila, R., 2006. Cooling kinetics experiments on different Stromboli lavas: effects on crystal morphologies and phase composition. Journal of Volcanology and Geothermal Research 155, 179-200.

Couch, S., Sparks, R.S.J., Carroll, M.R., 2003. The kinetics of degassinginduced crystallisation at Soufriere Hills volcano, Montserrat. J. Petrol. 44, 1477-1502

Chen, Y. and Zhang, Y., 2009. Clinopyroxene dissolution in basaltic melt. Geochimica et Cosmochimica Acta, 73, 5730-5747.

Crabtree, S. M. and Lange, R. A., 2011. Complex phenocryst textures and zoning patterns in andesites and dacites: evidence of degassing-induced rapid crystallization? J. Petrol. 52, 3-38.

Crisp, J., Baloga, S., 1990. A model for lava flows with two thermal components. J. Geophys. Res. 95, 1255-1270. http://dx.doi.org/10.1029/89JB01696.

Crisp, J., Cashman, C.K., Bonini, J.A., Hougen, S.B., Pieri, D.C., 1994. Crystallization history of the 1984 Mauna Loa lava flow. J. Geophys. Res. 99, 7177-7198

Davis, M.J., Ihinger, P.D., Lasaga, A.C., 1997. Influence of water on nucleation kinetics in silicate melt. J. Non-Cryst. Solids 219, 62-69

Deer,W.A., Howie, R.A., Zussman, J., 2001. Framework Silicates: Feldspars. second edition.

The Geological Society, London.

Del Gaudio, P.,Mollo, S., Ventura, G., Iezzi, G., Taddeucci, J., Cavallo, A., 2010. Cooling rate induced differentiation in anhydrous and hydrous basalts at $500 \mathrm{MPa}$ : implications for the storage and transport of magmas in dikes. Chem. Geol. 270, 164-178.

Delesse, M.A., 1847. Procédé mécanique pour déterminer la composition des roches. Comptes Rendus Hebdomadaires des Sciences de l'Academie de Sciences 25, 544-545 
Dingwell, D. B., \& Webb, S. L., 1990. Relaxation in silicate melts. European Journal of Mineralogy. 4, 427-449.

Donaldson, C.H., 1976. An experimental investigation of olivine morphology. Contrib. Mineral. Petrol. 57, 187-213

Dowty, E., 1980. Crystal growth and nucleation theory. In: Physics of Magmatic Processes. Hargraves R (ed) Princeton University Press, Princeton, NJ. p 487-551

Faure, F., Trolliard, G., Nicollet, C., Montel, J.M., 2003. A development model of olivine morphology as a function of the cooling rate and the degree of undercooling. Contributions to Mineralogy and Petrology, 145, 251-263.

Faure, F., Schiano, P., Trolliard, G., Nicollet, C., Soulestin, B., 2007. Textural evolution of polyhedral olivine experiencing rapid cooling rates. Contributions to Mineralogy and Petrology, $153,405-416$.

Freda C., Baker D.R., Ottolini L., 2001. Reduction of water loss from gold-palladium capsules during piston-cylinder experiments by use of pyrophyllite powder. Am. Min. 86:234-237

Freda, C., Gaeta, M., Misiti, V., Mollo, S., Dolfi, D., Scarlato, P., 2008. Magma-carbonate interaction: an experimental study on ultrapotassic rocks from Alban Hills (Central Italy). Lithos $101,397-415$.

Frey, H.M., Lange, R., 2011. Phenocryst complexity in andesites and dacites from the Tequila volcanic field, Mexico: resolving the effects of degassing vs. magma mixing. Contrib. Mineral. Petrol. 162, 415-445.

Hammer, J.E., 2006. Influence of $\mathrm{fO}_{2}$ and cooling rate on the kinetics and energetics of Fe-rich basalt crystallization. Earth and Planetary Science Letters 248, 618-637.

Hammer, J.E., 2008. Experimental studies of the kinetics and energetics of magma crystallization. 
In: Putirka, K.D., Tepley, F.J. (Eds.), Minerals, Inclusions and Volcanic Processes. Rev. Mineral. Geochem. 69, pp. 9-59.

Hammer, J.E., 2009. Application of a textural geospeedometer to late-stage magmatic history of MIL03346 Meteoritics Planet. Sci. 44, 141-154

Hammer, J. E. and Rutherford, M. J., 2002. An experimental study of the kinetics of decompression-induced crystallization in silicic melt. Journal of Geophysical Research: Solid Earth, 107(B1), ECV-8.

Hammer, J. E., Cashman, K. V., Hoblitt, R. P., Newman, S., 1999. Degassing and microlite crystallization during pre-climactic events of the 1991 eruption of Mt. Pinatubo, Philippines. Bulletin of Volcanology. 60, 355-380.

Hammer, J.E., Sharp, T.G., Wessel, P., 2010. Heterogeneous nucleation and epitaxial crystal growth of magmatic minerals. Geology 38, 367-370.

Hersum, T.G., Marsh, B.D., 2006. Igneous microstructures from kinetic models of crystallization. J Volcanol. Geotherm. Res. 154, 34-47

Higgins, M.D., 1998. Origin of anorthosite by textural coarsening: quantitative measurements of a natural sequence of textural development. Journal of Petrology 39, 1307-1323.

Higgins, M.D., 1999. Origin of megacrysts in granitoids by textural coarsening: a crystal size distribution (CSD) study of microcline in the Cathedral Peak Granodiorite, Sierra Nevada, California. Geological Society, London, Special Publications, 168, 207-219.

Higgins, M.D., 2000. Measurement of crystal size distributions. American Mineralogist 85, 11051116.

Higgins, M.D., 2006. Quantitative Textural Measurements in Igneous and Metamorphic Petrology. Cambridge University Press, Cambridge. 
Higgins, M.D., 2011. Textural coarsening in igneous rocks. International Geology Review, 53, 354-376.

Higgins, M. D.and Roberge, J., 2003. Crystal size distribution of plagioclase and amphibole from Soufriere Hills Volcano, Montserrat: evidence for dynamic crystallization-textural coarsening cycles. Journal of Petrology, 44, 1401-1411.

Iezzi, G., Mollo, S., Torresi, G., Ventura, G., Cavallo, A., Scarlato, P., 2011. Experimental solidification of an andesitic melt by cooling. Chem. Geol. http://dx.doi.org/10.1016/j. chemgeo.2011.01.024.

Iezzi, G., Mollo, S., Shaini, E., Cavallo, A., Scarlato, P., 2014. The cooling kinetics of plagioclase revealed by electron microprobe mapping. Am. Mineral. http://dx.doi.org/10.2138/am.2014.4626.

Kirkpatrick, R.J., 1975. Crystal growth from the melt-a review. American Mineralogist 60, 798814.

Kirkpatrick, R.J., 1981. Kinetics of crystallization of igneous rocks: In: Lasaga, A.C., Kirkpatrick, R.J. (Eds.), Reviews in Mineralogy, 8, pp. 321-395.

Kirkpatrick, R.J., 1983. Theory of nucleation in silicate melts. American Mineralogist 68, 66-77.

Kostov, I., Kostov, R.I., 1999. Crystal Habits of Minerals. Bulgarian Academic Monographs, Sophia.

Lanzafame, G., Mollo, S., Iezzi, G., Ferlito, C., Ventura, G., 2013. Unrevealing the solidification path of a pahoehoe "cicirara" lava from Mount Etna volcano. Bull. Volcanol. 75, 703.

Lasaga, A.C., 1997. Kinetic Theory in the Earth Sciences. Princeton University Press, Princeton, New York.

Le Bas, M. J., Le Maitre, R. W., Streckeisen, A., Zanettin, B., \& IUGS Subcommission on the Systematics of Igneous Rocks, 1986. A chemical classification of volcanic rocks based on the total alkali-silica diagram. J. Petrol. 27, 745-750. 
Lesher, C.E., Cashman, K.V., Mayfield, J.D., 1999. Kinetic controls on crystallization of Tertiary $10 \frac{1}{3} 16$ North Atlantic basalt and implications for the emplacement and cooling history of lava at Site 989, Southeast Greenland rifted margin. In: Larsen, H.C., Duncan, R.A., Allan, J.F., Brooks, K. (Eds.), 1018 8 1019

Lofgren, G.E., 1974. An experimental study of plagioclase morphology: Isothermal crystallization. American Journal of Science, 264, 243-273.

Lofgren, G.E. and Smith, D.P.,1980. The experimental determination of cooling rates of rocks: some complications. Lunar and Planetary Science, XI; 631-633, abstract.

Lofgren, G., \& Russell, W. J., 1986. Dynamic crystallization of chondrule melts of porphyritic and radial pyroxene composition. Geochimica et Cosmochimica Acta, 50, 1715-1726.

Lofgren, G.E., Donaldson, C.H., Williams, R.J., Mullins, O. Jr. and Usselman, T.M., 1974. Experimentally reproduced textures and mineral chemistry of Apollo 15 quartz-normative basalts. in: Proceedings of Lunar and Planetary Science Conference, V. Lunar and Planetary Institute, Houston, Texas, USA, 549-567

Lofgren, G.E., Huss, G.R. and Wasserburg, G.J., 2006. An experimental study of traceelement partitioning between Ti- Al- clinopyroxene and melt: Equilibrium and kinetic effects including sector zoning. American Mineralogist 91, 1596-1606.

Marsh, B.D., 1988. Crystal size distributions (CSD) in rocks and the kinetics and dynamics of crystallization I. Theory. Contrib. Mineral. Petrol. 99, 277-291

Marsh, B.D., 1998. On the interpretation of crystal size distributions in magmatic systems. Journal of Petrology 39, 553-599.

Marsh, B.D., 2007. Crystallization of silicate magmas deciphered using crystal size distributions. J Am. Ceramic. Soc. 90, 746-757 
Masotta, M., Freda, C., Gaeta, M., 2012. Origin of crystal-poor, differentiated magmas: insights from thermal gradient experiments. Contrib. Mineral. Petrol. 163, 49-65.

McMillan, P. F., and Wolf, G. H., 1995. Vibrational spectroscopy of silicate liquids. Reviews in Mineralogy and Geochemistry, 32, 247-315.

Means, W. D., and Park, Y., 1994. New experimental approach to understanding igneous texture. Geology, 22, 323-326.

Mollo, S. and Hammer, J. E., 2017. Dynamic crystallization in magmas. EMU Notes in Mineralogy, $16,373-418$.

Mollo, S., Del Gaudio, P., Ventura, G., Iezzi, G., Scarlato, P., 2010. Dependence of clinopyroxene composition on cooling rate in basaltic magmas: implications for thermobarometry. Lithos 118, $302-312$.

Mollo S., Putirka K., Iezzi G., Del Gaudio P., Scarlato P., 2011. Plagioclase-melt (dis)equilibrium due to cooling dynamics: implications for thermometry, barometry and hygrometry. Lithos 125, $221-235$

Mollo S., Misiti V., Scarlato P., Soligo M., 2012a. The role of cooling rate in the origin of high temperature phases at the chilled margin of magmatic intrusions. Chem. Geol. 322-323, 28-46

Mollo S., Iezzi G., Ventura G., Cavallo A., Scarlato P., 2012b. Heterogeneous nucleation mechanisms and formation of metastable phase assemblages induced by different crystalline seeds in a rapidly cooled andesitic melt. J. Non-Cryst. Solids 358, 1624-1628

Mollo, S., Blundy, J., Scarlato, P., Iezzi, G., Langone, A., 2013a. The partitioning of trace elements between clinopyroxene and trachybasaltic melt during rapid cooling and crystal growth. Contrib. Miner. Petrol. 166, 1633-1654. http://dx.doi.org/10.1007/s00410-013-0946-6.

Mollo, S., Putirka, K., Iezzi, G., Scarlato, P., 2013b. The control of cooling rate on titanomagnetite composition: implications for a geospeedometry model applicable to alkaline rocks from Mt. Etna volcano. Contrib. Mineral. Petrol. 165, 457-475. http://dx.doi.org/10.1007/s00410-012-0817-6. 
Mollo, S., Putirka, K., Misiti, V., Soligo, M., Scarlato, P., 2013c. A new test for equilibrium based 1083 on clinopyroxene-melt pairs: clues on the solidification temperatures of Etnean alkaline melts at post-eruptive conditions. Chem. Geol. 352, http://dx.doi.org/10.1016/j.chemgeo.2013.05.026.

Mollo S., Giacomoni P.P., Andronico D., Scarlato P., 2015a. Clinopyroxene and titanomagnetite cation redistributions at Mt. Etna volcano (Sicily, Italy): Footprints of the final solidification history of lava fountains and lava flows. Chem. Geol. 406, 45-54, http://dx.doi.org/10.1016/j

Mollo, S., Giacomoni, P.P., Coltorti, M., Ferlito, C., Iezzi, G., Scarlato, P., 2015b. Reconstruction of magmatic variables governing recent Etnean eruptions: constraints from mineral chemistry and P-T-fO2-H2O conditions. Lithos 212-215, 311-320.

Mollo, S., Blundy, J., Scarlato, P., De Cristofaro, S.P., Tecchiato, V., Di Stefano, F., Vetere, F., Holtz, F., Bachmann ,O., 2018, An integrated P-T-H2O-lattice strain model to quantify the role of clinopyroxene fractionation on REE $+\mathrm{Y}$ and HFSE patterns of mafic alkaline magmas: Application to eruptions at Mt. Etna. Earth-Science Reviews, 185, 32-56, https://doi.org/10.1016/j.earscirev.2018.05.014

Morimoto, N., 1988. Nomenclature of pyroxenes. Mineralogy and Petrology, 39, 55-76.

Moynihan, C. T., 1995. Structural relaxation and the glass transition. Reviews in Mineralogy and Geochemistry, 32, 1-19.

Müller-Krumbhaar, H., 1975. Diffusion theory for crystal growth at arbitrary solute concentration. The Journal of Chemical Physics, 63, 5131-5138.

Muncill, G.E., Lasaga, A.C., 1987. Crystal-growth kinetics of plagioclase in igneous systems: One atmosphere experiments and application of a simplified growth model. Am. Mineral. 72, 299-311

Muncill, G.E., Lasaga, A.C., 1988. Crystal-growth kinetics of plagioclase in igneous systems: Isothermal $\mathrm{H}_{2} \mathrm{O}$ saturated experiments and extension of a growth model to complex silicate melts. Am. Mineral. 73, 982- 992 
Ni, H., Keppler, H., Walte, N., Schiavi, F., Chen, Y., Masotta, M. and Li, Z., 2014. In situ observation of crystal growth in a basalt melt and the development of crystal size distribution in igneous rocks. Contributions to Mineralogy and Petrology, 167, 1003.

1119

Niederberger, M., Cölfen, H., 2006. Oriented attachment and mesocrystals: Non-classical crystallization mechanisms based on nanoparticle assembly. Physical Chemistry Chemical Physics $8,3271-3287$

O'driscoll, B., Donaldson, C. H., Troll, V. R., Jerram, D. A., Emeleus, C. H., 2006. An origin for $\mathbb{1} 1825$ harrisitic and granular olivine in the Rum Layered Suite, NW Scotland: a crystal size distribution study. Journal of Petrology, 48, 253-270.

Orlando, A., D’Orazio, M., Armienti, P., Borrini, D., 2008. Experimental determination of plagioclase and clinopyroxene crystal growth rates in an anhydrous trachybasalt from Mt Etna (Italy). Eur. J. Mineral. 20, 653-664, DOI:10.1127/ 0935-1221/2008/0020-1841.

Oze, C., and Winter, J. D., 2005. The occurrence, vesiculation, and solidification of dense blue glassy pahoehoe. Journal of Volcanology and Geothermal Research, 142, 285-301.

Park Y., Hanson B., 1999. Experimental investigation of Ostwald-ripening rates of forsterite in the haplobasaltic system. J. Volc. Geotherm. Res. 90, 103-113

Pupier, E., Duchene, S., Toplis, M.J., 2008. Experimental quantification of plagioclase crystal size distribution during cooling of basaltic liquid. Contrib. Mineral. Petrol. 155, 555-570.

Randolph, A.D., Larson, M.A., 1971. Theory of particulate processes. Academic Press, New York, $251 \mathrm{pp}$

Resmini, R. G., 2007. Modeling of crystal size distributions (CSDs) in sills. J. Volcan. Geotherm. Res., 161, 118-130.

Saltykov, S.A., 1949. Calculation of the distribution curves for the size of dispersed grains. Plant Laboratory. 15, 1317-1319 
Schiavi, F.,Walte, N., Keppler, H., 2009. First in situ observation of crystallization processes in a basaltic-andesitic melt with the moissanite cell. Geology 37, 963-966.

$\frac{1152}{6}$

Schwartz, H.A., 1939. Metallographic determination of the size distribution of tempered carbon nodules. Metals Alloys 5, 139-140

Sear, R.P., 2012. The non-classical nucleation of crystals: microscopic mechanisms and applications to molecular crystals, ice and calcium carbonate. International Materials Reviews 57, 328-356

Shea, T.,Hammer, J.E., 2013. Kinetics of decompression and cooling-induced crystallization of mafic-intermediate hydrous magmas. J. Volcanol. Geotherm. Res. 260, 127-145.

Shea, T., Lynn, K. J., \& Garcia, M. O., 2015. Cracking the olivine zoning code: Distinguishing between crystal growth and diffusion. Geology, 43, 935-938.

Simakin, A.G., Salova, T.P., Armienti, P., 2003. Kinetics of clinopyroxene growth from a hydrous hawaiite melt. Geochem. Intl. 41, 1165-1175

Soule, S.A., Cashman, K.V., Kauahikaua, J.P., 2004. Examining flow emplacement through the surface morphology of three rapidly emplaced, solidified lava flows, Kilauea Volcano, Hawaii. Bull. Volcanol. 66, 1-14.

Špillar, V. and DolejŠ , D., 2013. Calculation of time-dependent nucleation and growth rates from quantitative textural data: inversion of crystal size distribution. J. Petrol., 54, 913-931.

Stewart, M. L. and Pearce, T. H., 2004. Sieve-textured plagioclase in dacitic magma: Interference imaging results. American Mineralogist, 89, 348-351.

Sunagawa, I., 1981. Characteristics of Crystal Growth in Nature as Seen from the Morphology of Mineral Crystals. Bulletin de Mineralogie. 104. 81-87. 
Sunagawa, I., 2005. Crystals: growth, morphology and perfection. Cambridge University Press, Cambridge

Teng, H.R., 2013. How ions and molecules organize to form crystals. Elements 9 (3), 189-194.

Underwood E. E. 1968. Surface area and length in volume. In Quantitative microscopy, edited by DeHoff R. T. and Rhines F. N. New York: McGraw-Hill. pp. 78-127.

Vetere, F., Iezzi, G., Behrens, H., Cavallo, A., Misiti, V., Dietrich, M., Knipping, J., Ventura, G. and Mollo, S., 2013. Intrinsic solidification behaviour of basaltic to rhyolitic melts: A cooling rate experimental study. Chemical Geology, 354, 233-242.

Vetere, F., Iezzi, G., Behrens, H., Holtz, F., Ventura, G., Misiti, V., Cavallo, A., Mollo, S. and Dietrich, M., 2015. Glass forming ability and crystallisation behaviour of subalkaline silicate melts. Earth Science Reviews, 150, 25-44.

Walker D., Kirkpatrick R. J., Longhi J., and Hays J. F., 1976. Crystallization history of lunar picritic basalt sample 12002; phase-equilibria and cooling-rate studies. Geological Society of America Bulletin 87, 646-656.

Walker, D., Powell, M. A., Hays, J. F., \& Lofgren, G. E., 1978. Dynamic crystallization of a eucrite basalt. In Lunar and Planetary Science Conference Proceedings. 9, 1369-1391.

Waters, C. and Boudreau, A. E., 1996. A reevaluation of crystal-size distributions in chromite cumulates. American Mineralogist, 81, 1452-1459.

Waters, L.E., Andrews, B.J. and Lange, R.A., 2015. Rapid crystallization of plagioclase phenocrysts in silicic melts during fluid-saturated ascent: Phase equilibrium and decompression experiments. Journal of Petrology, 56, 981-1006.

Watson, E.B. and Muller, T., 2009. Non-equilibrium isotopic and elemental fractionation during diffusion controlled crystal growth under static and dynamic conditions. Chemical Geology, 267, 111-124. 
$12_{3}^{2} 16$ Webb, S., 1997. Silicate melts: Relaxation, rheology, and the glass transition. Reviews of 1217 Geophysics. 35, 191-218.

Webb, S. L., Dingwell, D. B., 1995. Viscoelasticity. Reviews in Mineralogy and Geochemistry, 32, 95-119.

Zhang, Y., 2010. Diffusion in minerals and melts: theoretical background. in: Diffusion in Minerals and Melts (Y. Zhang and D. Cherniak, editors). Rev. Mineral. Geochem. 72, 5-60

Welsch, B., Hammer, J.E. and Hellebrand, E., 2014. Phosphorus zoning reveals dendritic architecture of olivine. Geology, 42, 867-870.

Zhang, Y., Ni, H., \& Chen, Y., 2010. Diffusion data in silicate melts. Rev. Mineral. Geochem. 72, 311-408.

Zieg, M.J., Marsh, B.D., 2002. Crystal size distribution and scaling laws in the quantification of igneous textures. Journal of Petrology 43, 85-101.

Zieg, M.J., Lofgren, G.E., 2006. An experimental investigation of texture evolution during continuous cooling. J. Volc. Geotherm. Res. 154, 74-88. 
a)

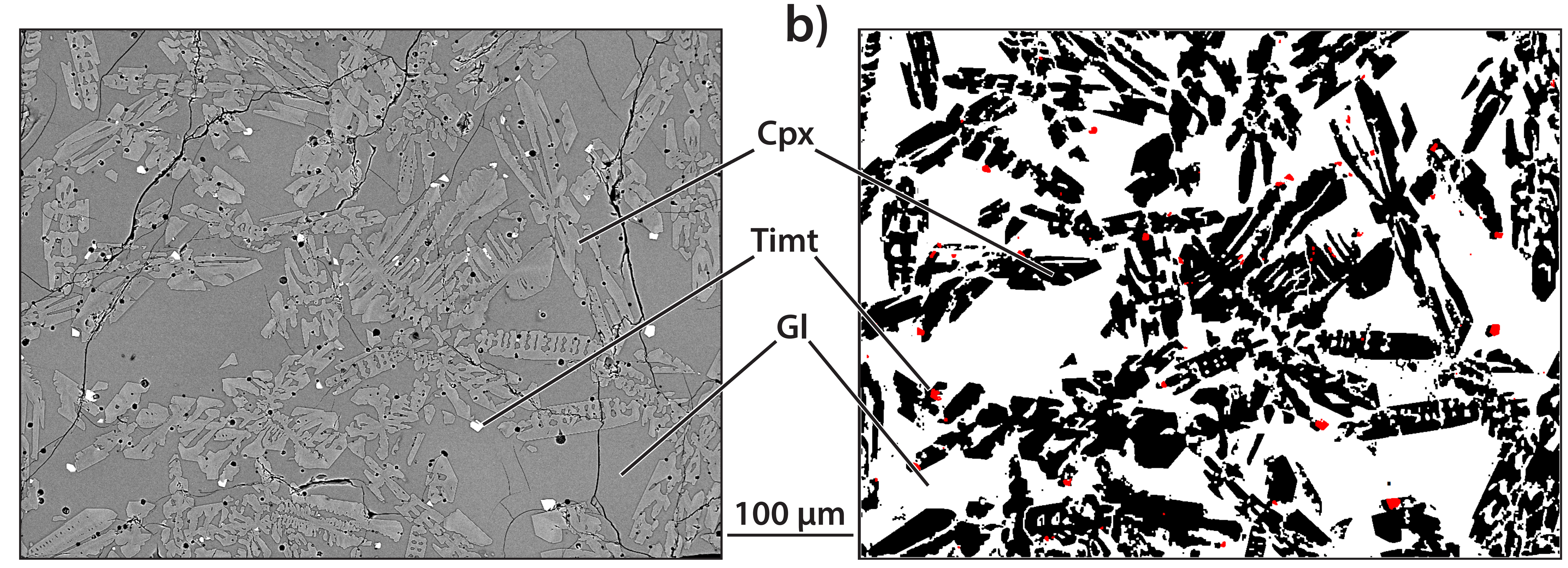

Fig. 1. Explanatory illustration of the image segmentation procedure. Original BSE image showing clinopyroxene (Cpx), titanomagnetite (Timt) and glass (Gl) (a). Thresholding procedure conducted through the ImageJ code and binarization of the image identifying clinopyroxene (black), titanomagnetite (red) and glass (white). Cpx, clinopyroxene. Timt, titanomagnetite. Gl, glass. 
$0.5 \mathrm{~h}$
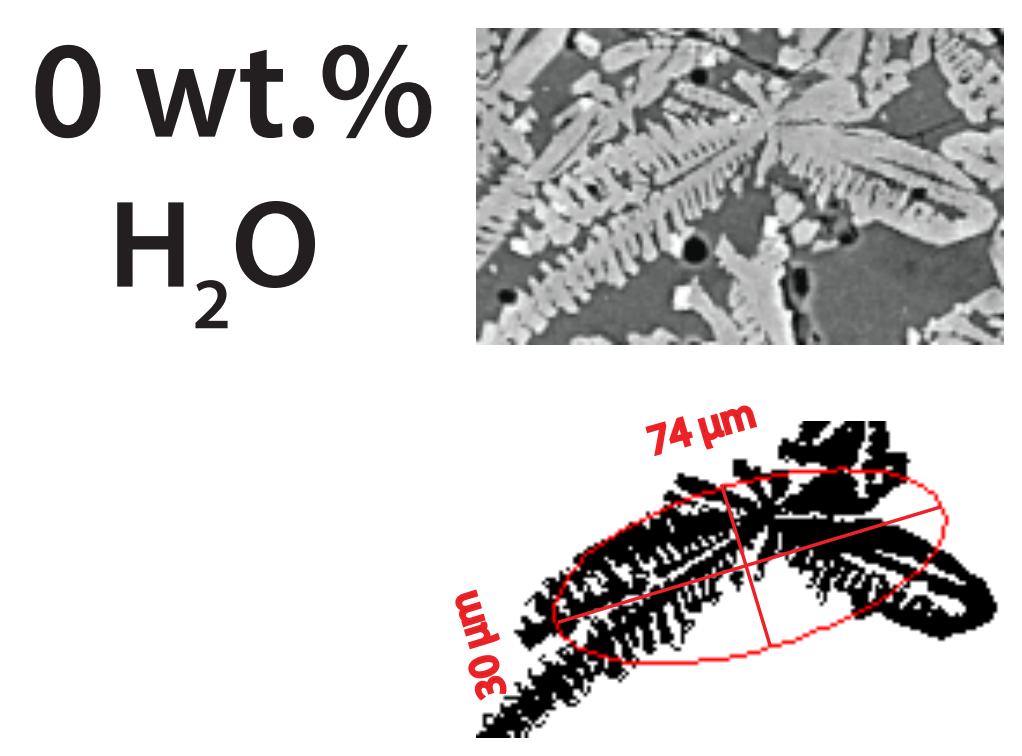

$1 \mathrm{~h}$
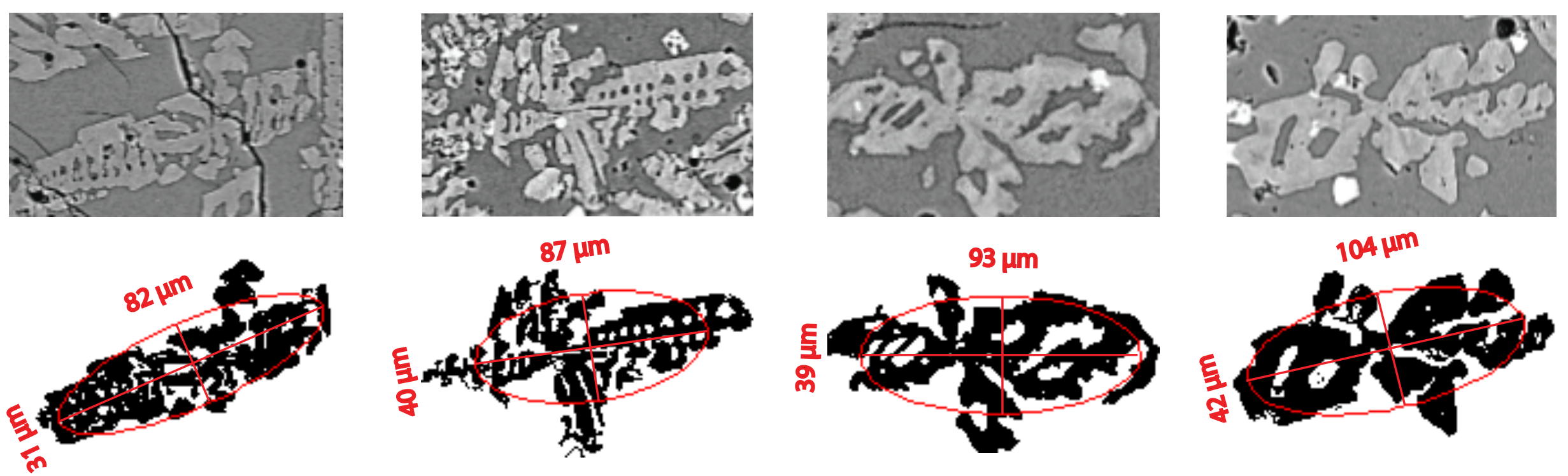

$104 \mu \mathrm{m}$
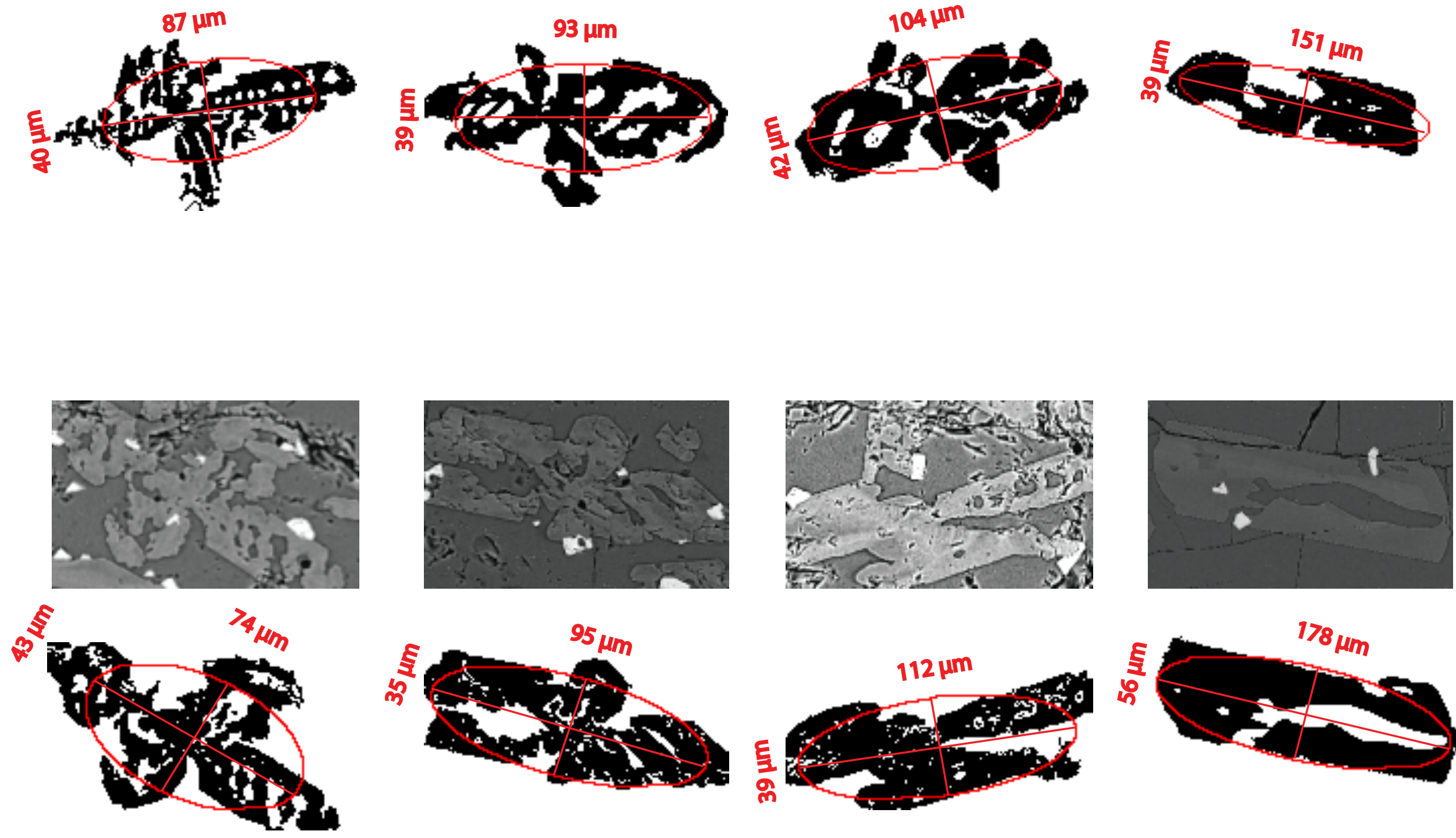

$24 \mathrm{~h}$
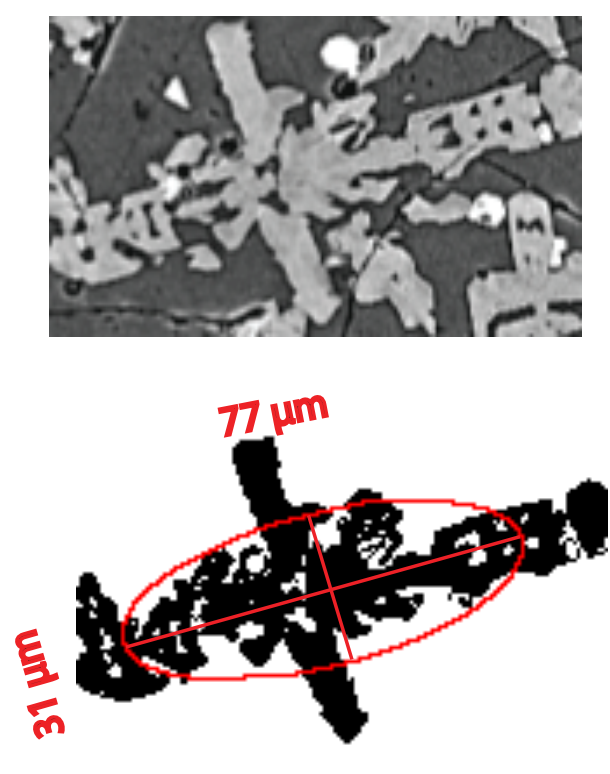
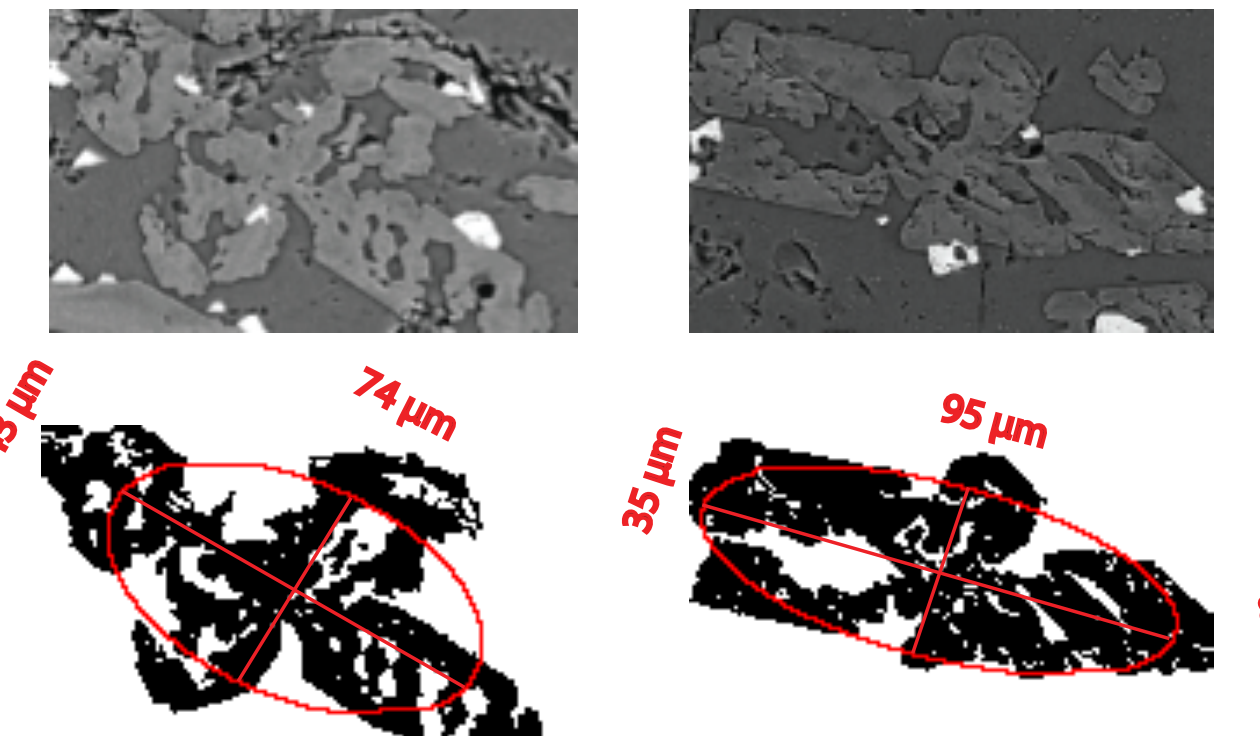
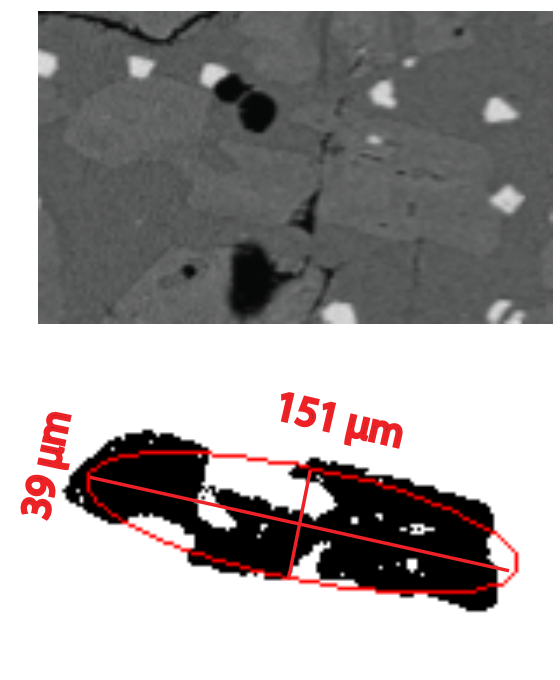

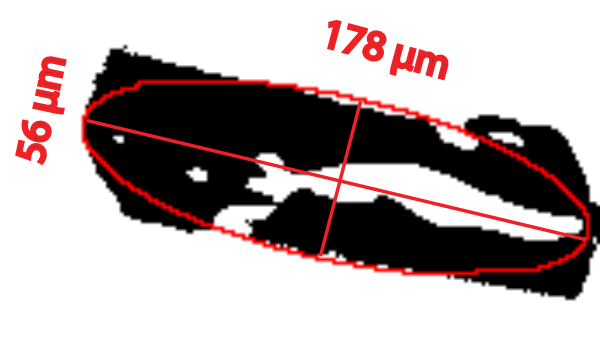

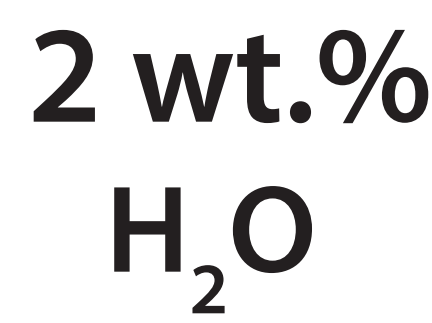

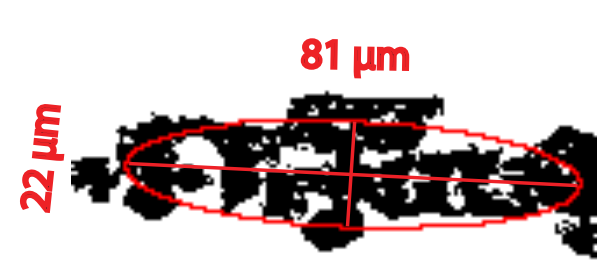

Fig. 2. Textural development of clinopyroxene crystals from anhydrous and hydrous time-series experiments. Equal-area best-fit ellipses (with major and minor axes) are derived by the ImageJ code and superimposed on the segmented clinopyroxene crystals. 

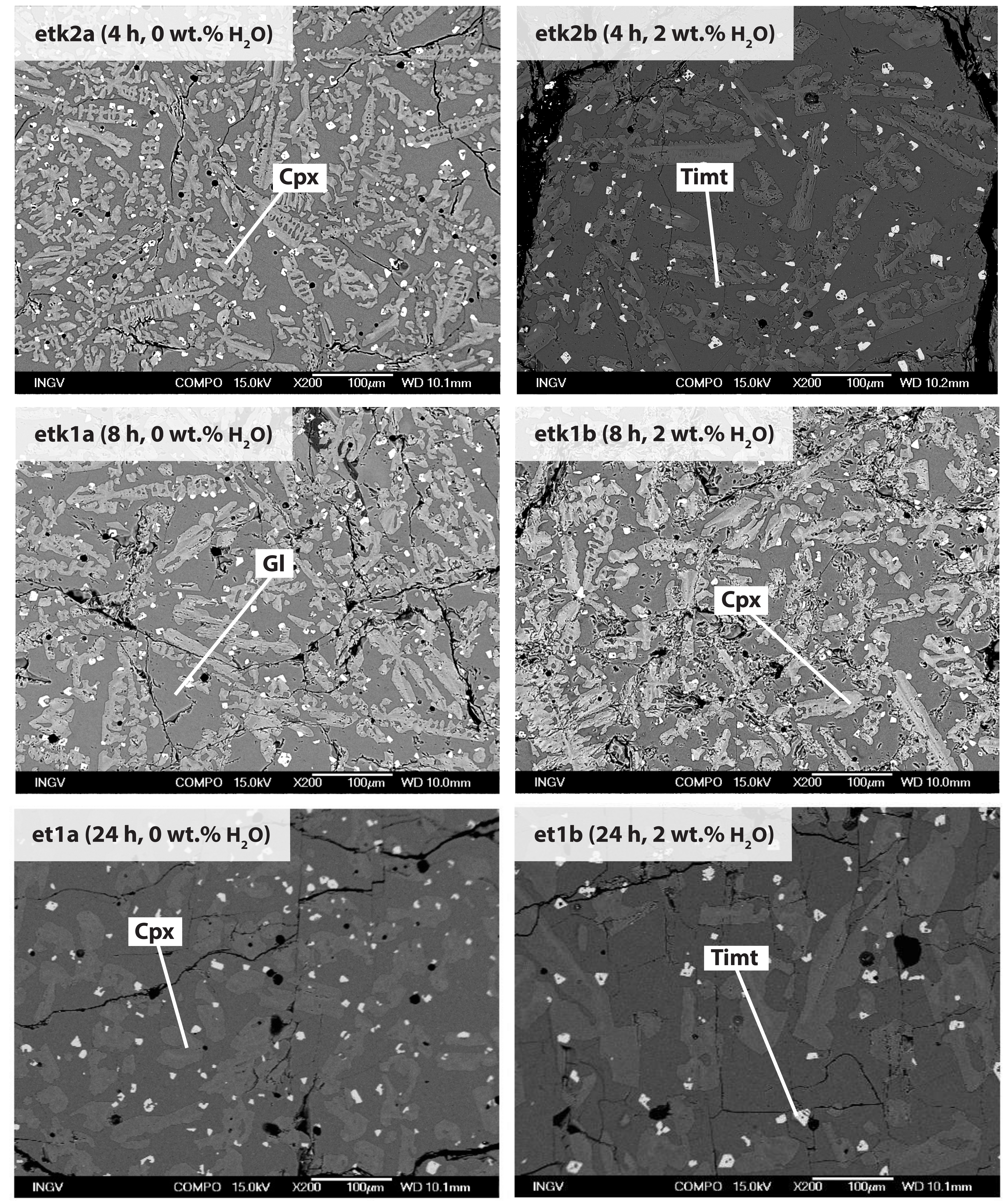

Fig. 3. Backscattered electron (BSE) images of experimental run products from anhydrous and hydrous time series. Cpx, clinopyroxene. Timt, titanomagnetite. Gl, glass 
a)

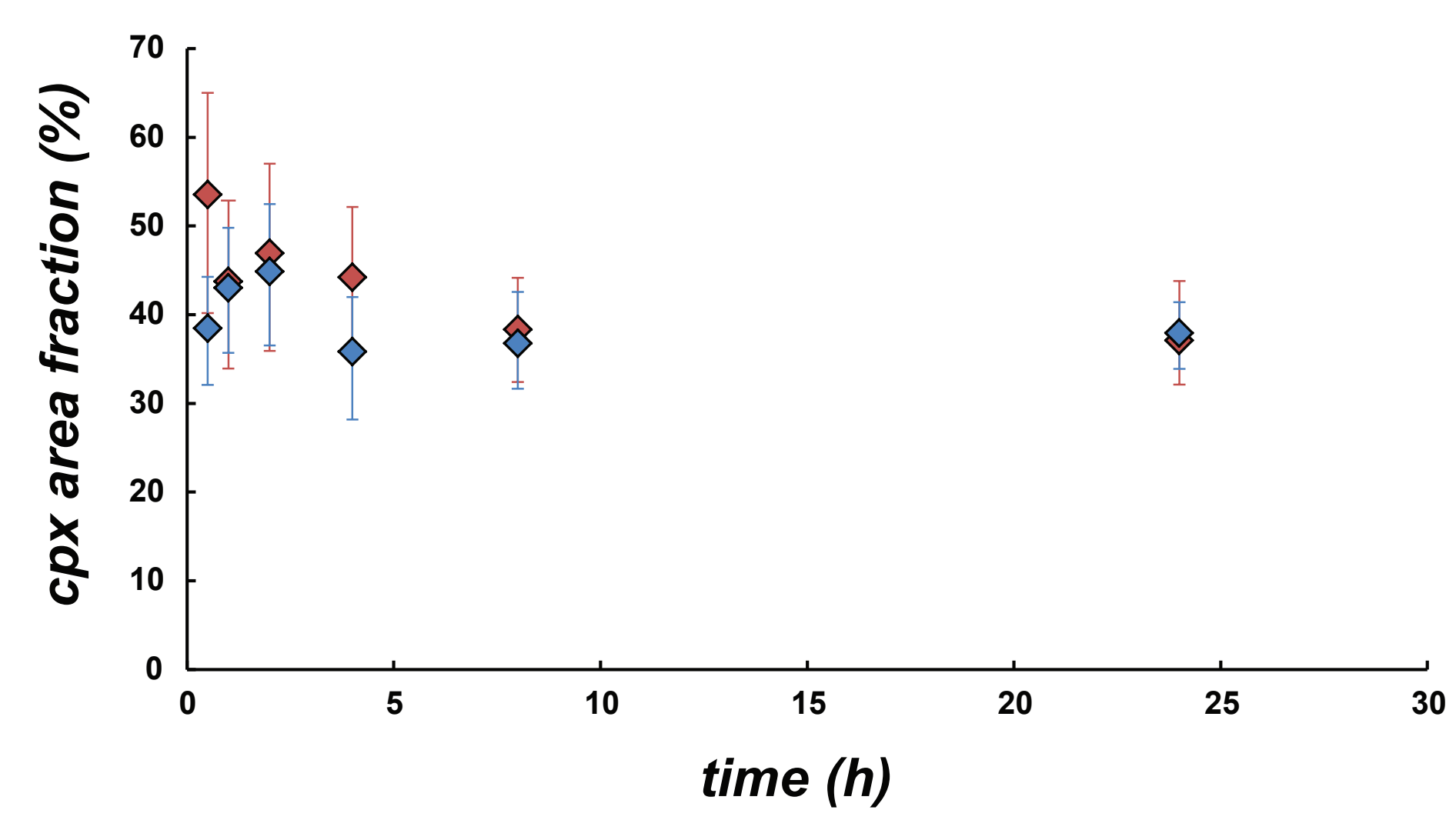

c)

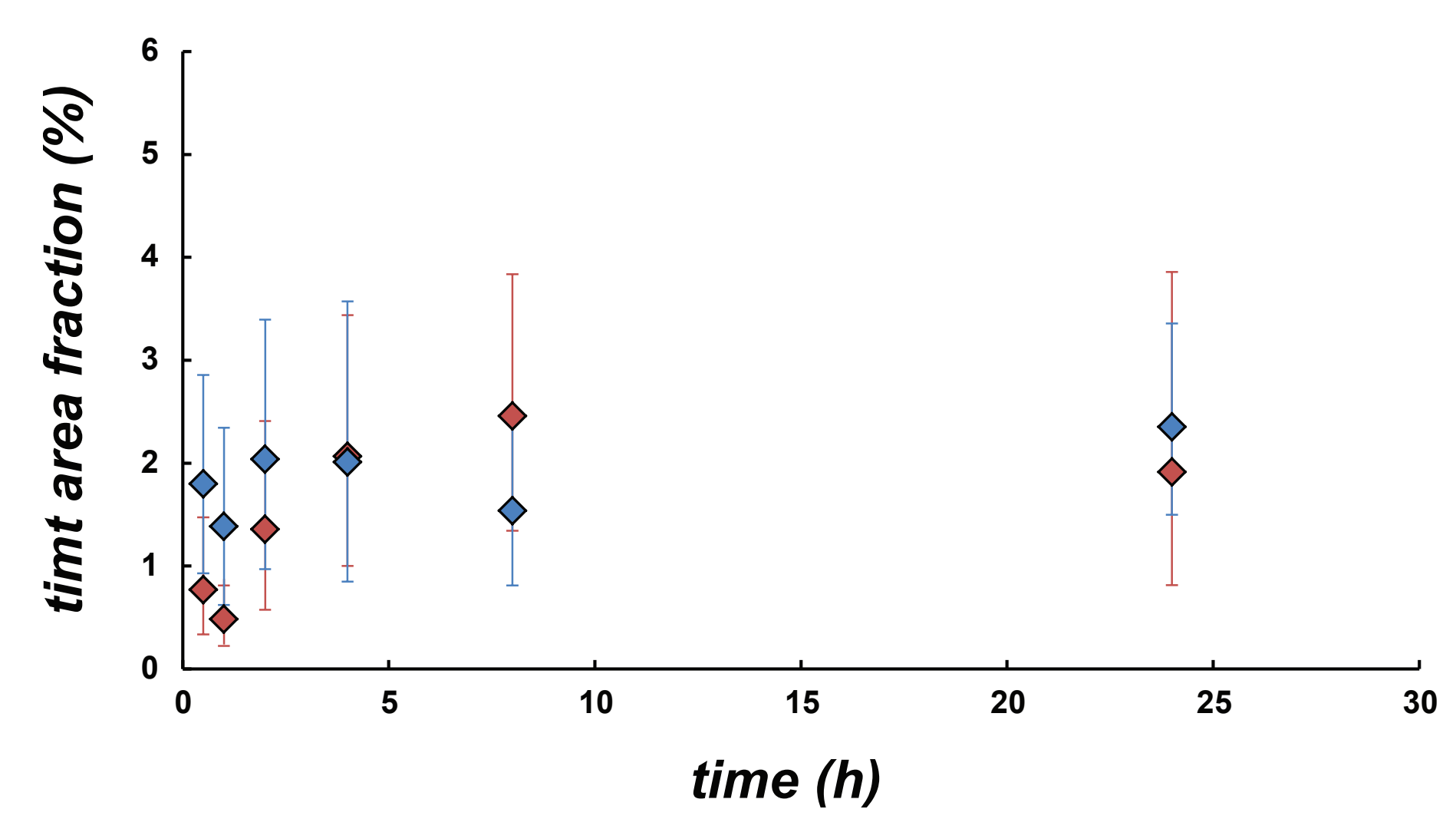

\section{b)}

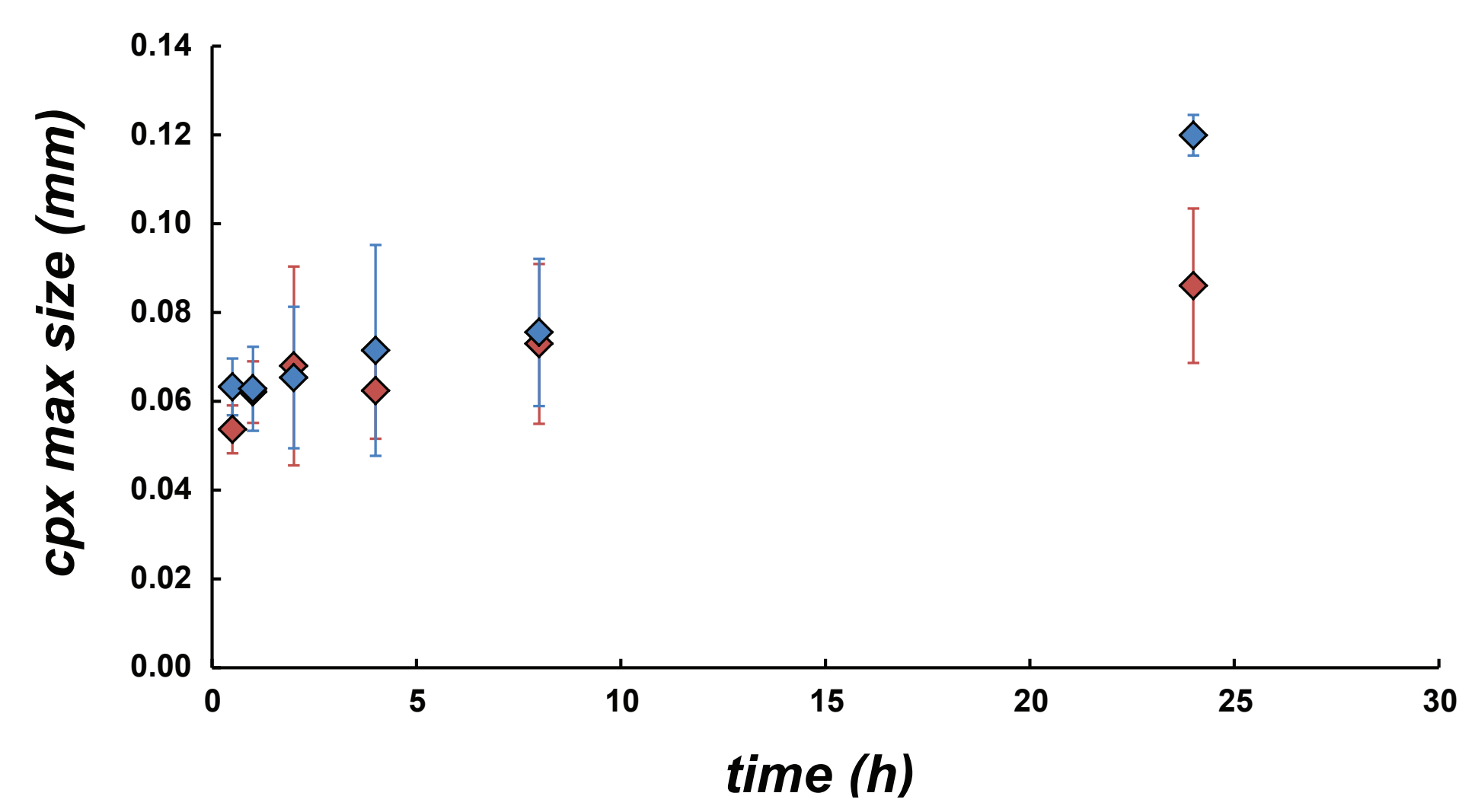

d)

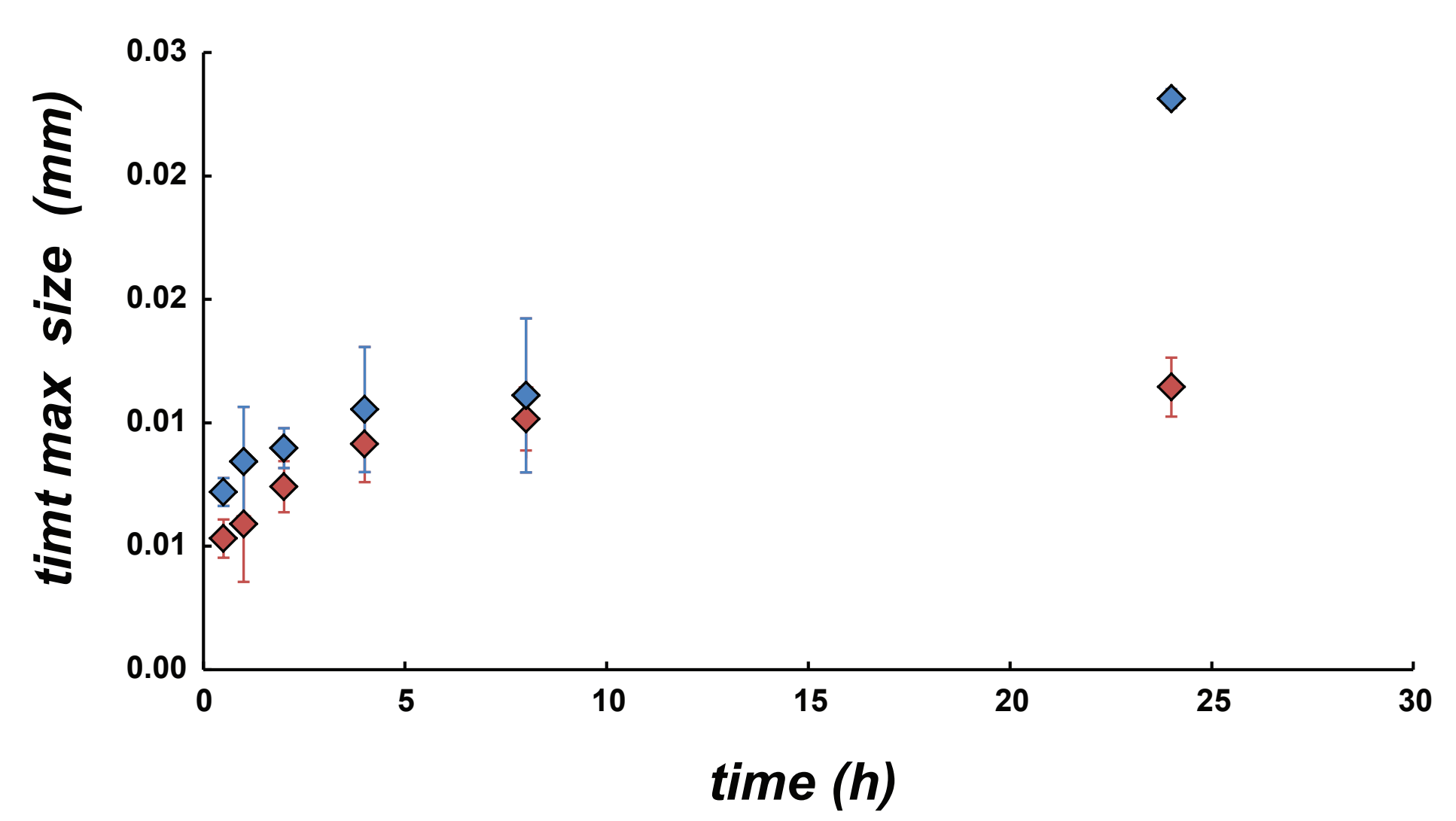

$\diamond 0 w t . \% \mathrm{H}_{2} \mathrm{O} \quad \diamond 2 \mathrm{wt} . \% \mathrm{H}_{2} \mathrm{O}$

Fig. 4. Variations of clinopyroxene and titanomagnetite textural parameters with dwell time. Clinopyroxene area fraction (a) and maximum crystal size (b). Titanomagnetite area fraction (c) and maximum crystal size (d). Cpx, clinopyroxene. Timt, titanomagnetite. 


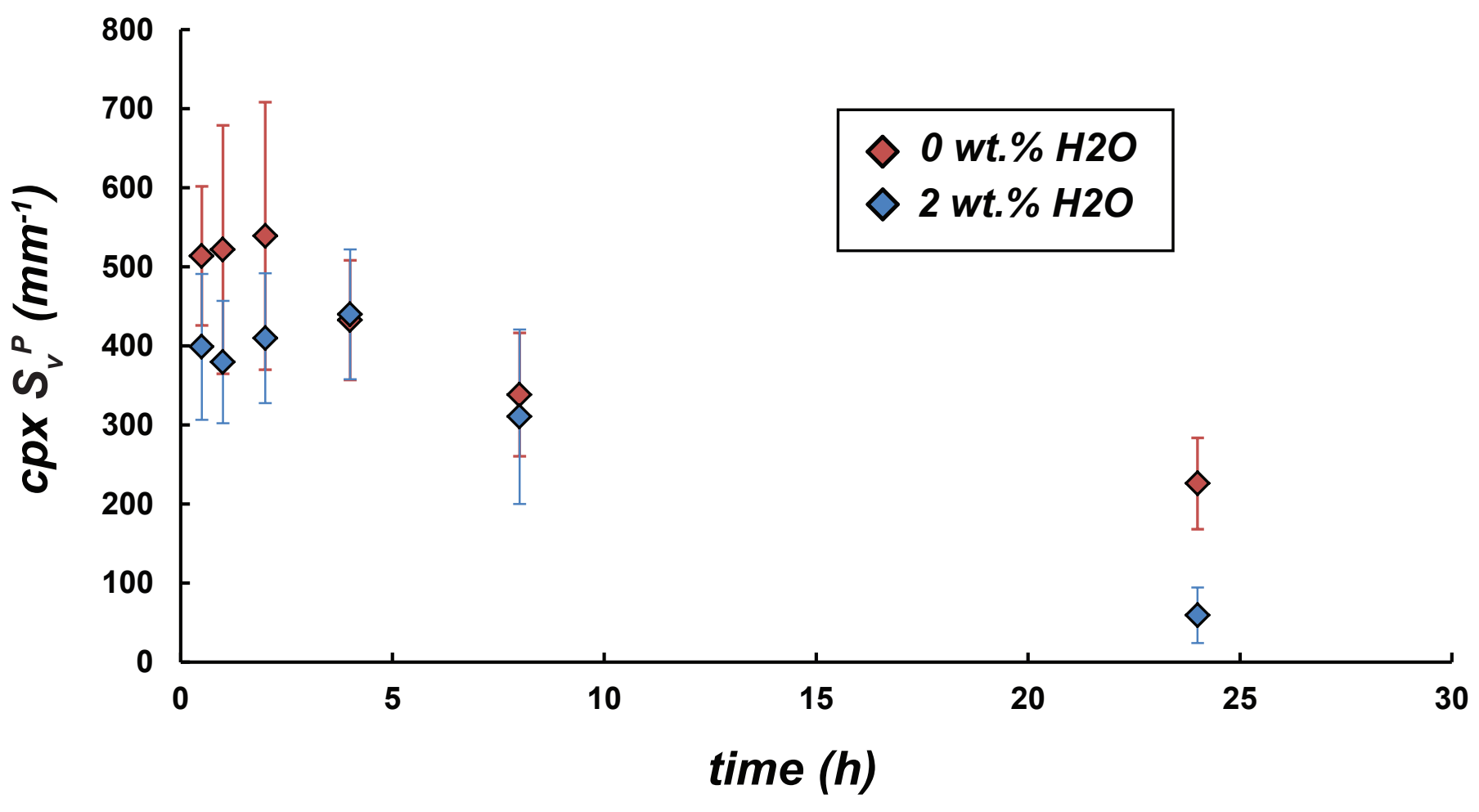

Fig. 5. Variation of surface area to volume ratio $\left(S_{v}^{P}\right)$ parameter of clinopyroxene with dwell time for both anhydrous (red diamonds) and hydrous (blue diamonds) time-series experiments. 

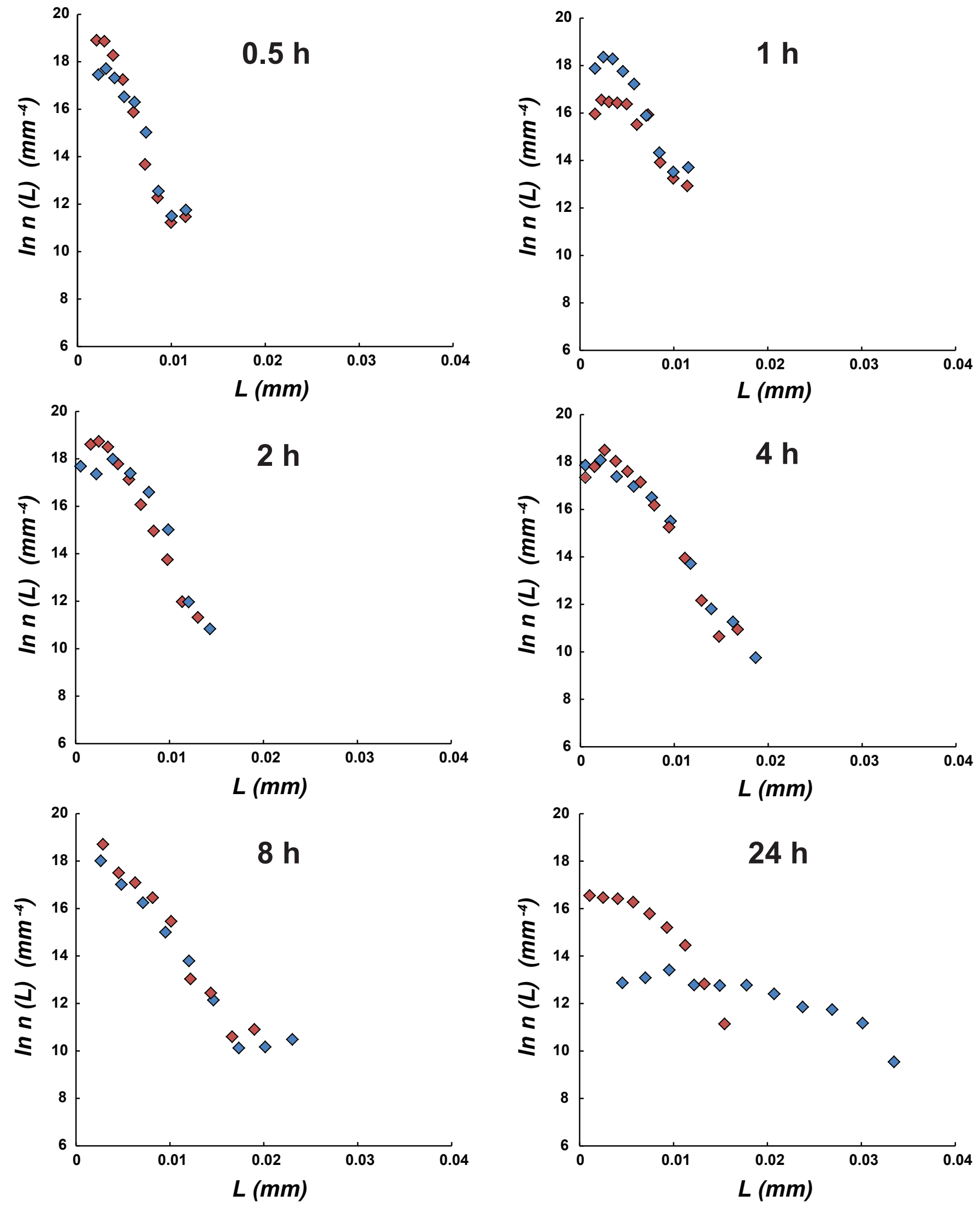

\section{$\diamond 0$ wt.\% $\mathrm{H}_{2} \mathrm{O} \quad \diamond 2$ wt. $\% \mathrm{H}_{2} \mathrm{O}$}

Fig.6. Crystal Size Distribution (CSD) analysis of titanomagnetite for both anhydrous (red diamonds) and hydrous (blue diamonds) time-series experiments. 


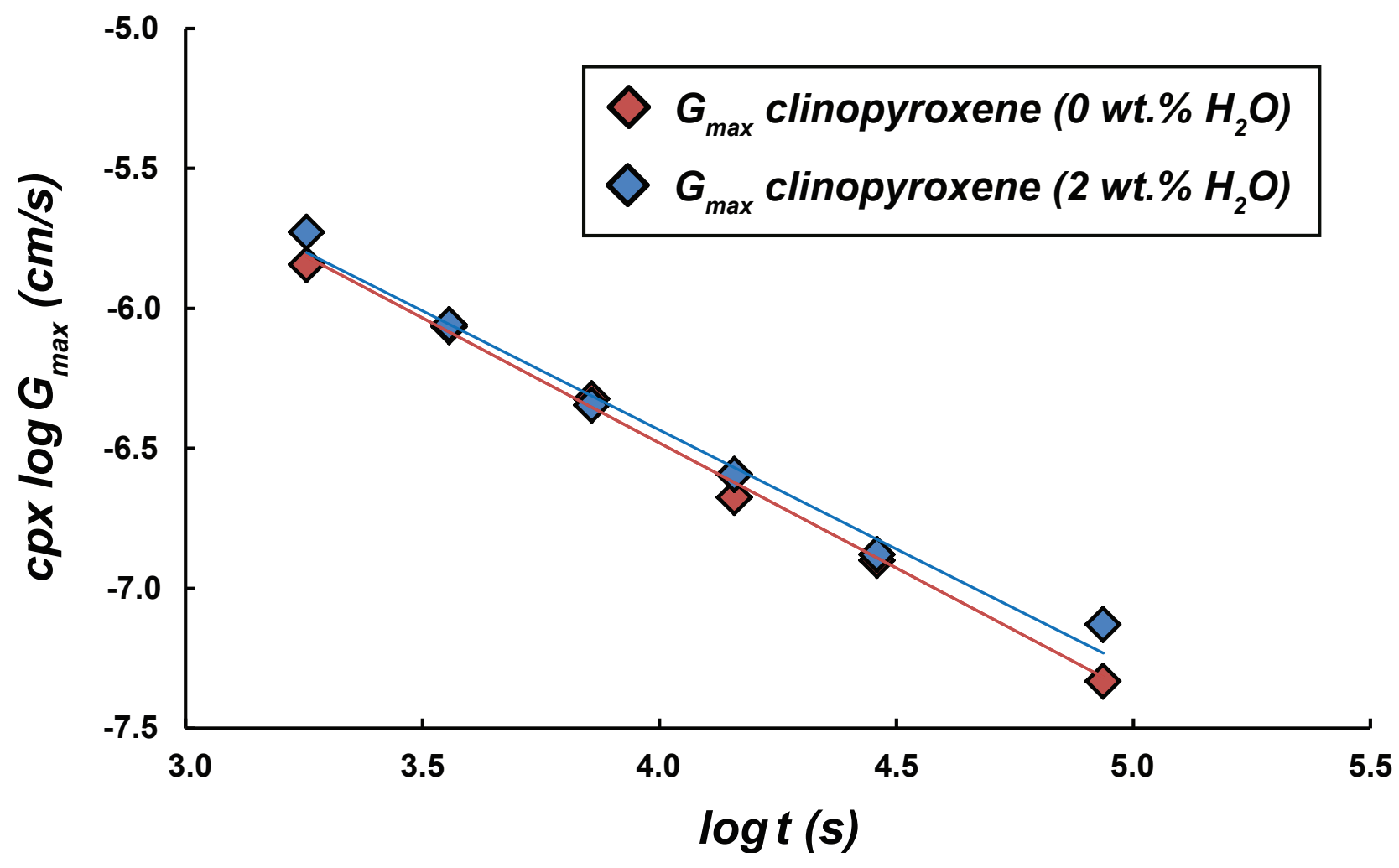

Fig. 7. $\log G_{\max } v s . \log t$ diagram based on clinopyroxene data from anhydrous and hydrous experiments. 

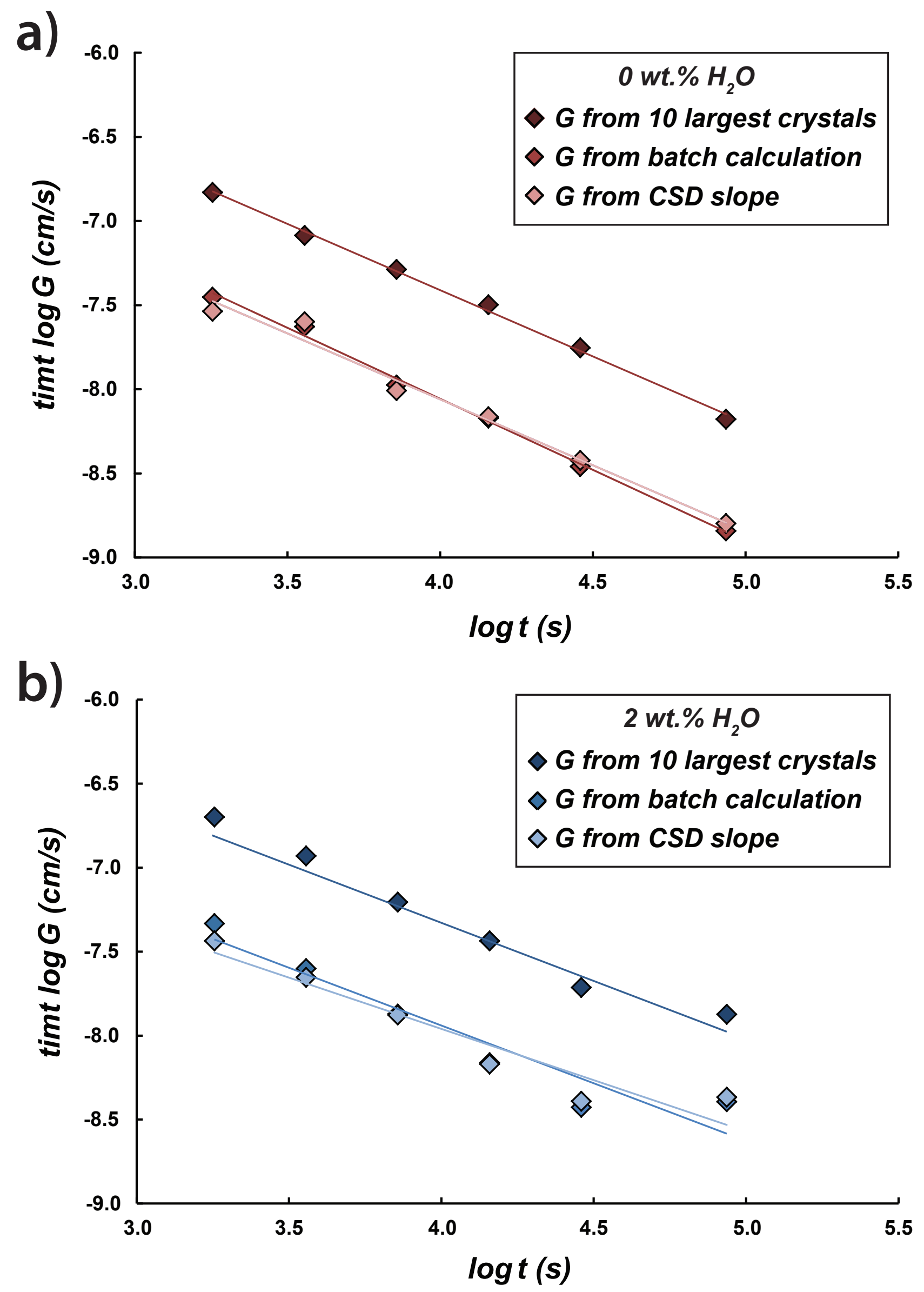

Fig. 8. $\log G$ vs. $\log t$ diagram based on titanomagnetite data from anhydrous (a) and hydrous (b) experiments. 

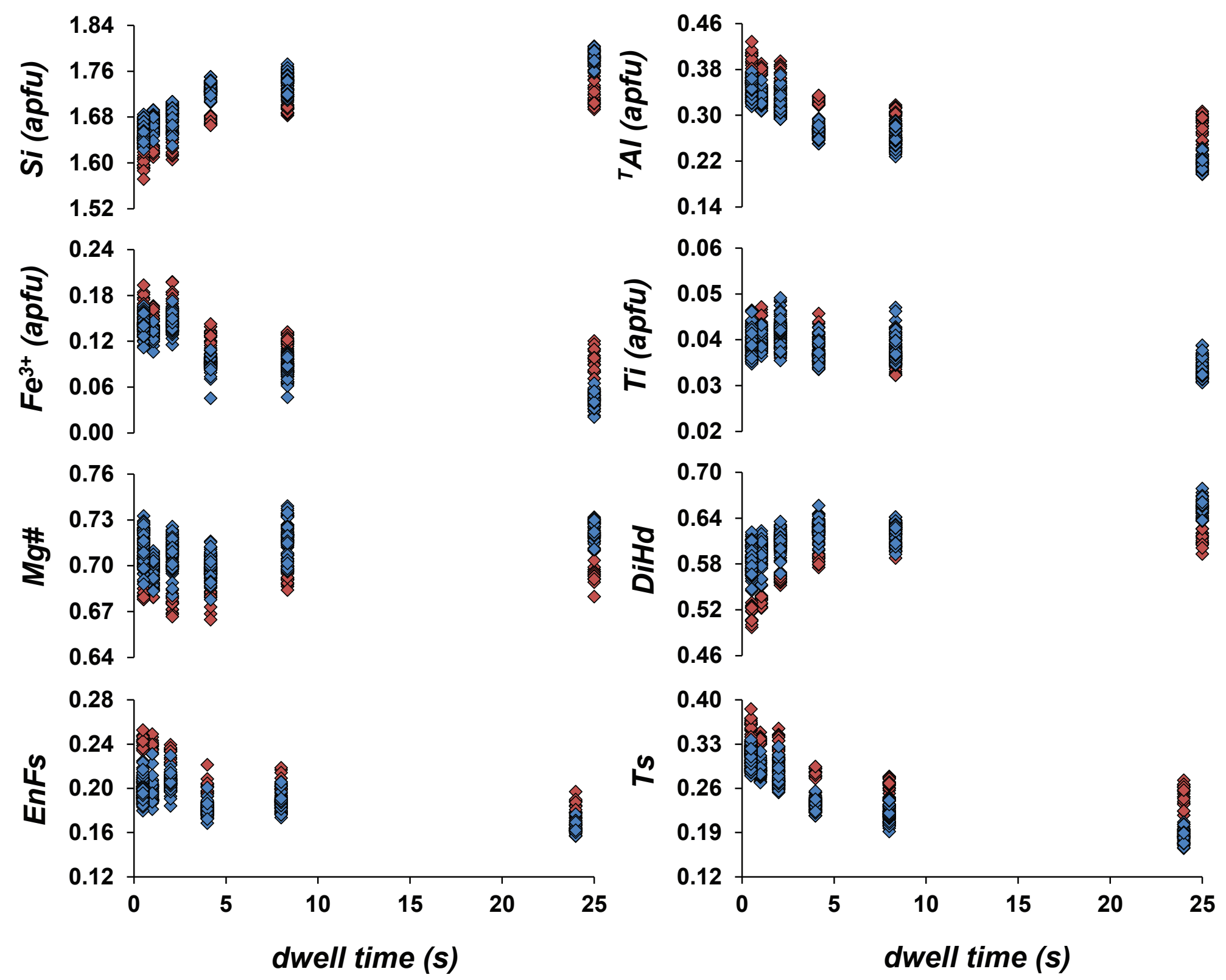

$\diamond 0$ wt. $\%$ H2O
$\diamond 2$ wt. $\%$ H2O

Fig. 9. Clinopyroxene compositional variation as a function of dwell time. $\mathrm{Mg} \#=100 \times \mathrm{Mg} /\left(\mathrm{Mg}+\mathrm{Fe}_{\mathrm{tot}}\right)$ on molar basis. $\mathrm{DiHd}=$ diopside $(\mathrm{Di})+$ hedenbergite $(\mathrm{Hd}) . \mathrm{EnFs}=$ enstatite $(\mathrm{En})+$ ferrosilite $(\mathrm{Fs}) . \mathrm{Ts}=$ Ca-Tschermak (CaTs) + CaTi-Tschermak (CaTiTs) + CaFe-Tschermak (CaFeTs). 
a)
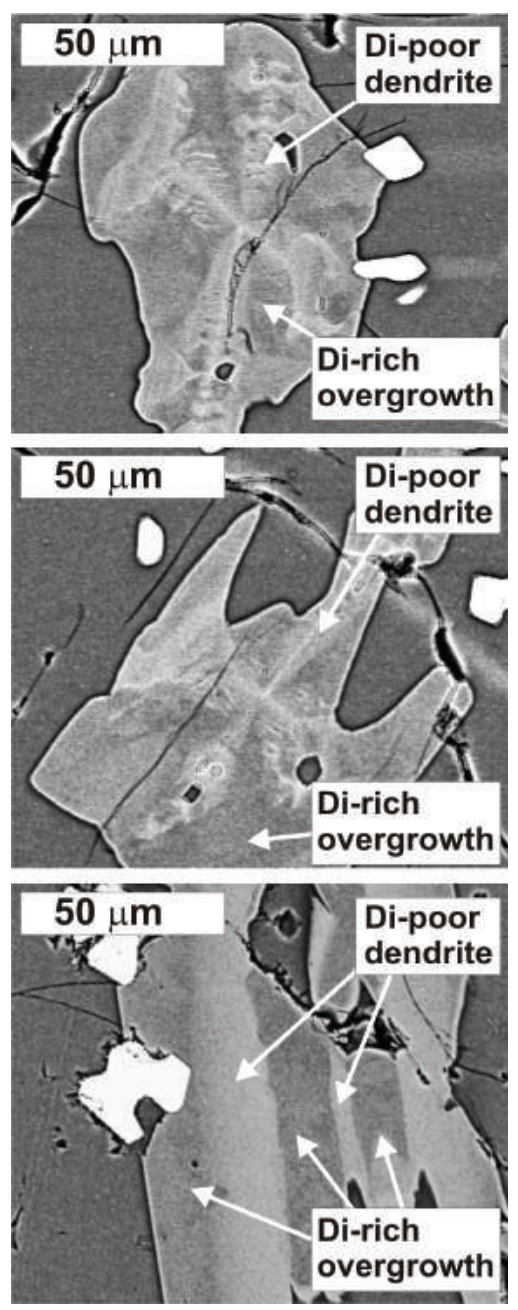

b)

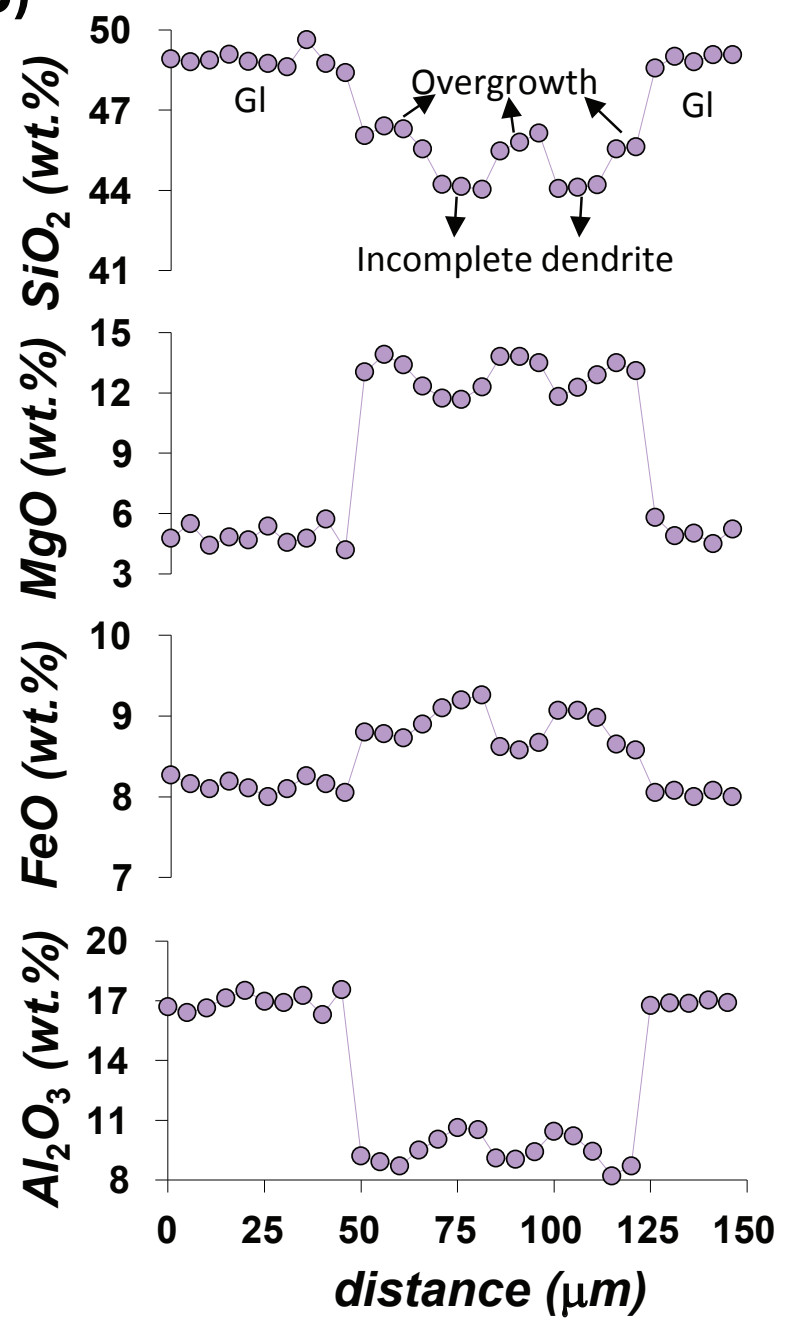

Fig. 10. Clinopyroxene Di-poor and Di-rich compositional variations revealed by backscattered electron (BSE) microphotographs (a). The high contrast used for the image highlights as Fe cations in clinopyroxene backscatter electrons better than $\mathrm{Mg}$ ones. Example of electron microprobe profile (i.e., 5- $\mu \mathrm{m}$-step traverses) for $\mathrm{SiO} 2, \mathrm{MgO}, \mathrm{Al} 2 \mathrm{O} 3$, and $\mathrm{FeO}$ analyzed across the crystal and surrounding glass (b). The complex zoning pattern is characterized by overgrowth of Di-rich and well-faced crystals onto early-formed Di-poor dendrites. 


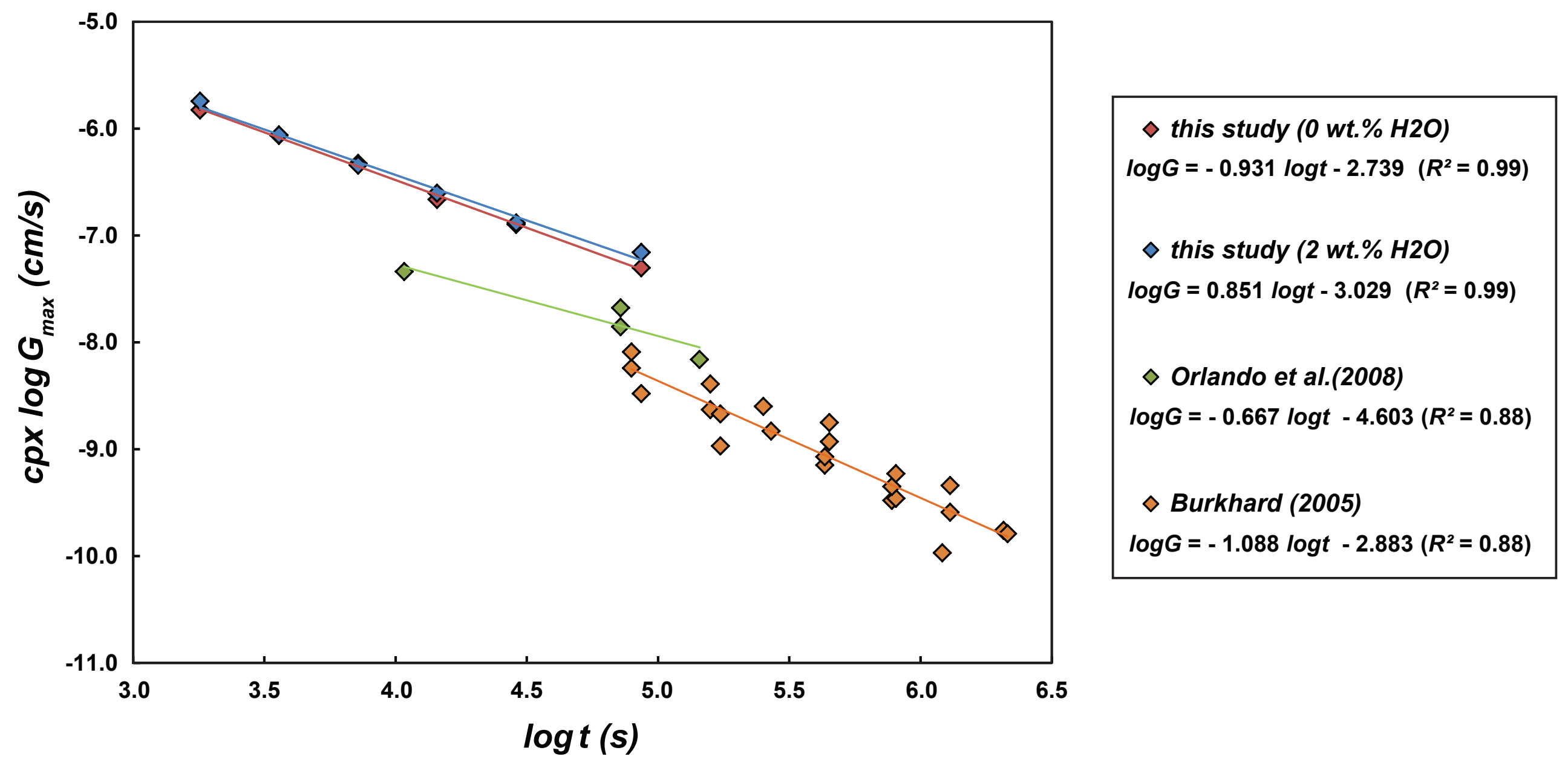

Fig. 11. $\log G$ vs. $\log t$ diagram in which clinopyroxene data from this study are compared with those from the experimental studies of Orlando et al. (2008) and Burkhard (2005). 
a)

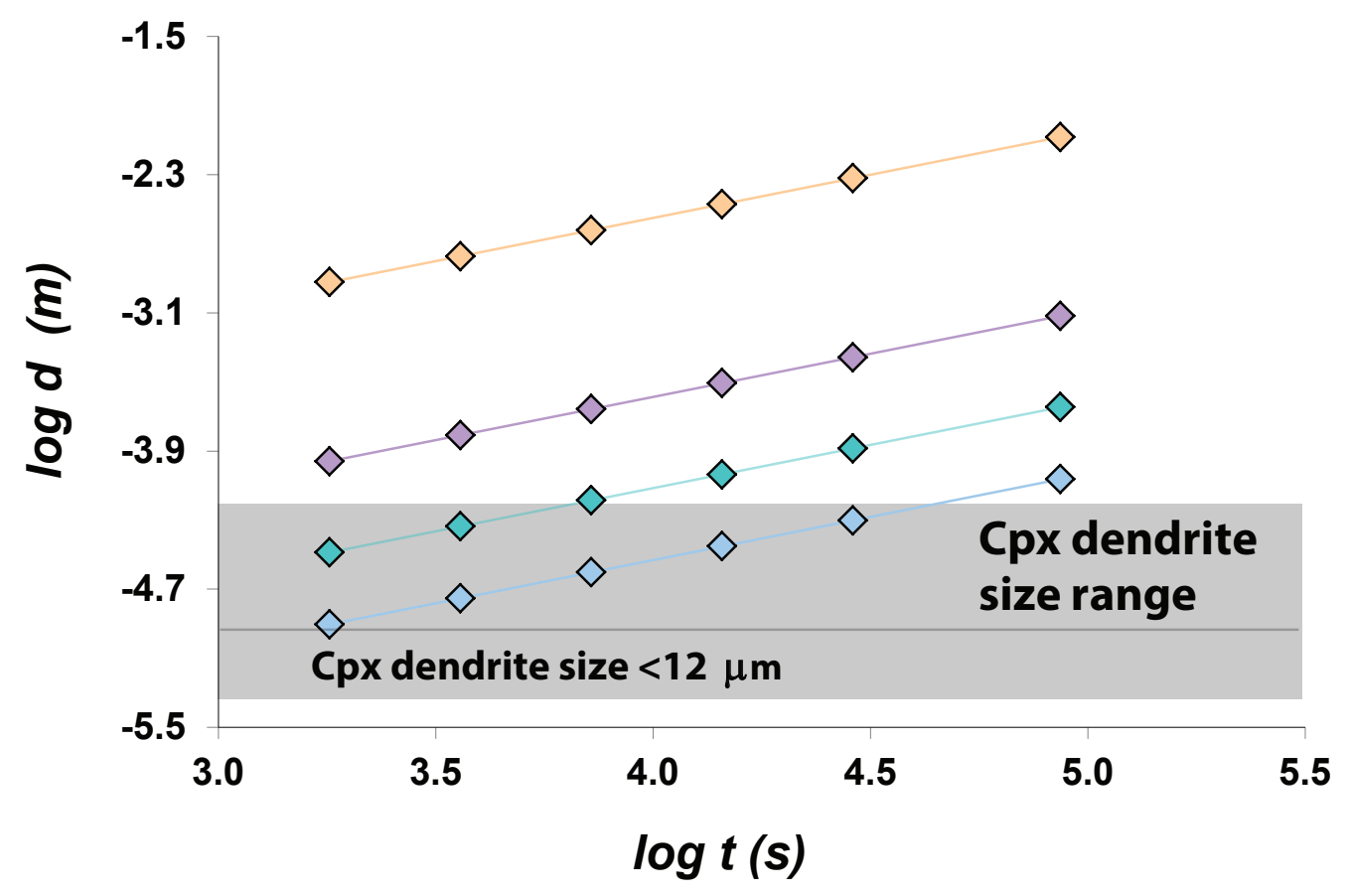

$\diamond$ Diffusion lenght of $\mathrm{Mg} \diamond$ Diffusion lenght of $\mathrm{Ca}$

$\diamond$ Diffusion lenght of $\mathrm{Al} \diamond$ Diffusion lenght of $\mathrm{Na}$

b)

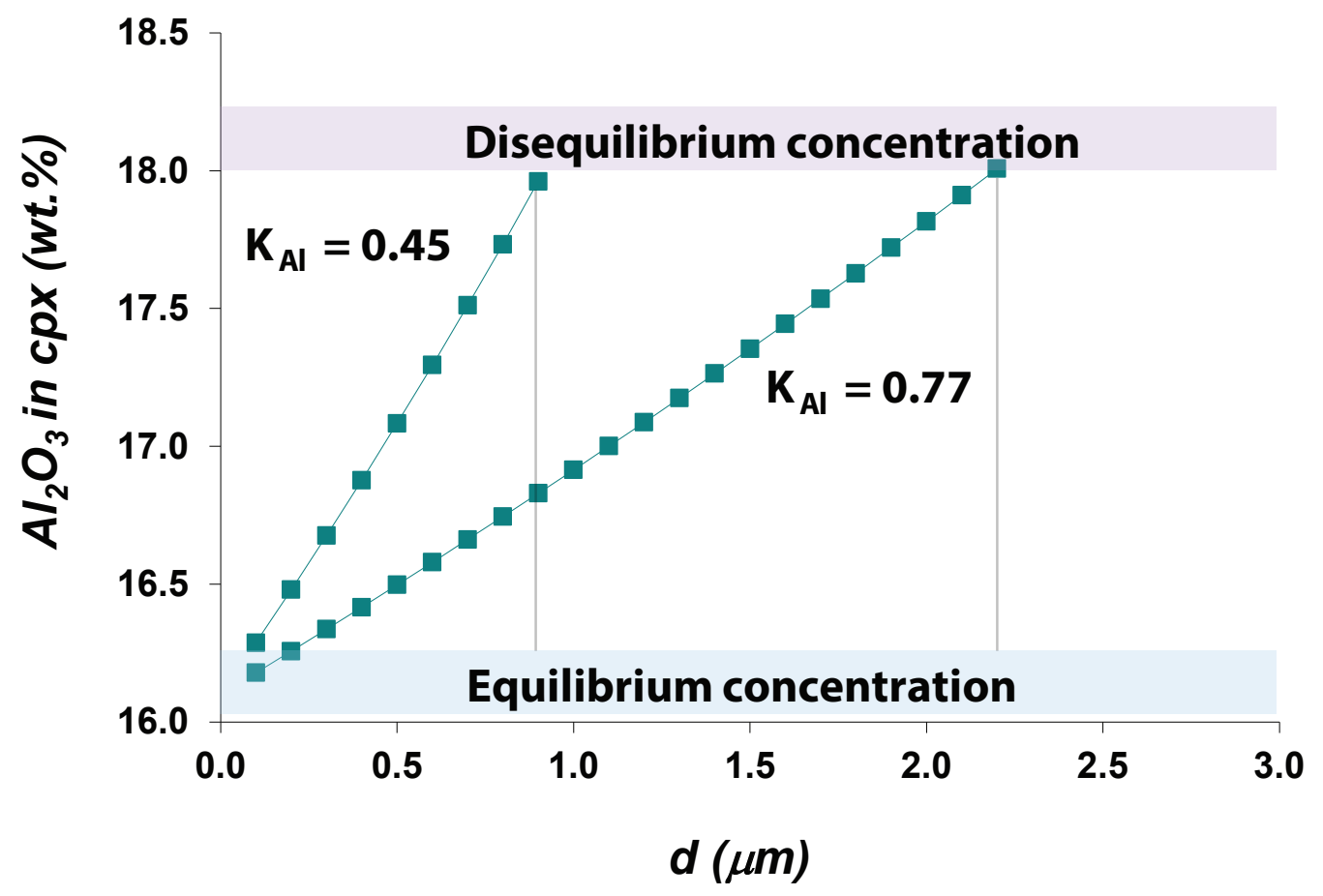

Fig. 12. Log-log diagram showing the diffusion length $(\log d)$ plotted against the experimental dwell time $(\log t)(a)$. The size of single and isolate dendrites is also reported for comparison as a grey area. Modelling data from the equation of Watson and Muller (2009) showing the control of the thickness (d) of the diffusive boundary layer in the melt on the $\mathrm{Al}_{2} \mathrm{O}_{3}$ concentration of clinopyroxene (b). 
Click here to download Table: Table 1_Pontesilli et al.docx

\begin{tabular}{cccccc}
\hline $\begin{array}{c}\text { Run } \\
(\#)\end{array}$ & $\begin{array}{c}\mathrm{P} \\
(\mathrm{MPa})\end{array}$ & $\begin{array}{c}\mathrm{T} \\
\left({ }^{\circ} \mathrm{C}\right)\end{array}$ & $\begin{array}{c}\mathrm{H}_{2} \mathrm{O} \\
(\mathrm{wt} . \%)\end{array}$ & $\begin{array}{c}\text { time } \\
(\mathrm{h})\end{array}$ & $\begin{array}{c}\mathrm{fO}_{2} \text { redox } \\
\text { buffer }\end{array}$ \\
\hline etk5a & 400 & 1100 & 0 & 0.5 & $\mathrm{NNO}+2$ \\
etk4a & 400 & 1100 & 0 & 1 & $\mathrm{NNO}+2$ \\
etk3a & 400 & 1100 & 0 & 2 & $\mathrm{NNO}+2$ \\
etk2a & 400 & 1100 & 0 & 4 & $\mathrm{NNO}+2$ \\
etk1a & 400 & 1100 & 0 & 8 & $\mathrm{NNO}+2$ \\
et1a & 400 & 1100 & 0 & 24 & $\mathrm{NNO}+2$ \\
etk5b & 400 & 1100 & 2 & 0.5 & $\mathrm{NNO}+2$ \\
etk4b & 400 & 1100 & 2 & 1 & $\mathrm{NNO}+2$ \\
etk3b & 400 & 1100 & 2 & 2 & $\mathrm{NNO}+2$ \\
etk2b & 400 & 1100 & 2 & 4 & $\mathrm{NNO}+2$ \\
etk1b & 400 & 1100 & 2 & 8 & $\mathrm{NNO}+2$ \\
et1b & 400 & 1100 & 2 & 24 & $\mathrm{NNO}+2$ \\
\hline
\end{tabular}

Table 1. Run conditions adopted for the time-series experiments. 
Click here to download Table: Table 2_Pontesilli et al.docx

\begin{tabular}{|c|c|c|c|c|c|c|c|c|c|c|}
\hline \multirow{2}{*}{$\begin{array}{l}\text { Run } \\
\text { (\#) }\end{array}$} & \multirow{2}{*}{$\begin{array}{c}\mathrm{H}_{2} \mathrm{O} \\
\text { (wt.\%) }\end{array}$} & \multirow{2}{*}{$\begin{array}{l}\text { time } \\
\text { (h) }\end{array}$} & \multicolumn{2}{|c|}{ area fraction } & \multicolumn{2}{|c|}{$L_{\max }$} & \multicolumn{2}{|c|}{$G_{\max } \times 10^{7}$} & \multicolumn{2}{|c|}{$S_{v}^{P}($ Hammer, 2006) } \\
\hline & & & $(\%)$ & $\sigma$ & $(\mu \mathrm{m})$ & $\sigma(10)$ & $(\mathrm{cm} / \mathrm{s})$ & $\sigma(10)$ & $\left(\mathrm{mm}^{-1}\right)$ & $\sigma$ \\
\hline etk5a & 0 & 0.5 & 53.53 & 12.41 & 53.66 & 5.39 & 14.91 & 1.50 & 513.84 & 87.93 \\
\hline etk4a & 0 & 1 & 43.73 & 9.48 & 62.07 & 6.96 & 8.62 & 0.97 & 521.89 & 157.36 \\
\hline etk3a & 0 & 2 & 46.92 & 10.57 & 67.96 & 22.39 & 4.72 & 0.16 & 539.32 & 169.19 \\
\hline etk2a & 0 & 4 & 44.20 & 8.33 & 62.40 & 10.83 & 2.17 & 0.38 & 432.59 & 75.62 \\
\hline etk1a & 0 & 8 & 38.31 & 5.89 & 72.92 & 18.03 & 1.27 & 0.30 & 338.42 & 78.16 \\
\hline et1a & 0 & 24 & 37.10 & 5.83 & 86.01 & 17.39 & 0.50 & 0.10 & 225.98 & 57.83 \\
\hline etk5b & 2 & 0.5 & 38.46 & 6.09 & 63.24 & 6.41 & 18.02 & 2.49 & 398.81 & 92.31 \\
\hline etk4b & 2 & 1 & 43.03 & 7.06 & 62.82 & 9.49 & 8.73 & 1.32 & 379.58 & 77.33 \\
\hline etk3b & 2 & 2 & 44.87 & 7.96 & 65.34 & 15.96 & 4.54 & 1.11 & 409.97 & 82.13 \\
\hline etk2b & 2 & 4 & 35.82 & 6.90 & 71.45 & 23.73 & 2.48 & 0.82 & 439.87 & 82.16 \\
\hline etk1b & 2 & 8 & 36.76 & 5.44 & 75.52 & 16.57 & 1.31 & 0.29 & 310.44 & 110.32 \\
\hline et1b & 2 & 24 & 37.92 & 3.76 & 119.93 & 4.60 & 0.69 & 0.03 & 59.33 & 34.98 \\
\hline
\end{tabular}

Table 2. Textural parameters and growth rates estimated for clinopyroxene. $\mathrm{L}_{\max }$ : maximum crystal length, average of 10 largest crystals. $\mathrm{G}_{\mathrm{max}}$ : maximum crystal growth rate, average of 10 largest crystals. $S_{v}^{P}$ : surface area to volume ratio, calculated according to Hammer (2006). See text for equations defining the parameters. 
Click here to download Table: Table 3_Pontesilli et al.docx

\begin{tabular}{|c|c|c|c|c|c|c|c|c|c|c|c|c|c|c|c|}
\hline \multirow{2}{*}{$\begin{array}{l}\text { Run } \\
(\#)\end{array}$} & \multirow{2}{*}{$\begin{array}{c}\mathrm{H}_{2} \mathrm{O} \\
(w t . \%)\end{array}$} & \multirow{2}{*}{$\begin{array}{l}\text { time } \\
\text { (h) }\end{array}$} & \multicolumn{2}{|c|}{ area fraction } & \multicolumn{2}{|c|}{$\mathrm{L}_{\max }$} & \multicolumn{2}{|c|}{$\mathrm{G}_{\max } \times 10^{7}$} & \multirow{2}{*}{$\begin{array}{c}\mathrm{G}_{\text {batch }} \times 10^{7} \\
(\mathrm{~cm} / \mathrm{s})\end{array}$} & \multirow{2}{*}{$\begin{array}{c}\mathrm{G}_{\mathrm{CSD}} \times 10^{7} \\
(\mathrm{~cm} / \mathrm{s})\end{array}$} & \multirow{2}{*}{$\begin{array}{c}d \\
d(\mu m)\end{array}$} & \multirow{2}{*}{$\begin{array}{c}L_{d} \\
L_{d}(\mu m)\end{array}$} & \multirow{2}{*}{$\begin{array}{c}\mathrm{N}_{\mathrm{A}} \\
\left(\mathrm{mm}^{-2}\right)\end{array}$} & \multirow{2}{*}{$\begin{array}{c}\text { slope } \\
1)\end{array}$} & \multirow{2}{*}{$\begin{array}{l}\text { CSD } \\
\text { intercept }\left(\mathrm{mm}^{-4}\right)\end{array}$} \\
\hline & & & $(\%)$ & $\sigma$ & $(\mu \mathrm{m})$ & $\sigma(10)$ & $(\mathrm{cm} / \mathrm{s})$ & $\sigma(10)$ & & & & & & & \\
\hline etk5a & 0 & 0.5 & 0.77 & 0.68 & 5.31 & 0.78 & 1.48 & 0.22 & 0.35 & 0.29 & 2.54 & 1.04 & 1174.07 & -957.42 & 21.67 \\
\hline etk4a & 0 & 1 & 0.48 & 0.41 & 5.90 & 2.35 & 0.82 & 0.28 & 0.24 & 0.25 & 3.39 & 1.81 & 205.46 & -551.91 & 18.86 \\
\hline etk3a & 0 & 2 & 1.36 & 1.21 & 7.41 & 1.04 & 0.51 & 0.07 & 0.11 & 0.10 & 3.05 & 1.41 & 1519.44 & -708.21 & 20.64 \\
\hline etk2a & 0 & 4 & 2.07 & 1.81 & 9.15 & 1.55 & 0.32 & 0.05 & 0.07 & 0.07 & 3.88 & 1.97 & 1556.48 & -506.60 & 19.38 \\
\hline etk1a & 0 & 8 & 2.46 & 2.12 & 10.16 & 1.28 & 0.18 & 0.04 & 0.03 & 0.04 & 4.00 & 2.17 & 1540.74 & -459.16 & 18.95 \\
\hline et1a & 0 & 24 & 1.91 & 1.71 & 11.45 & 1.20 & 0.07 & 0.01 & 0.01 & 0.02 & 4.97 & 2.75 & 792.43 & -363.64 & 17.79 \\
\hline etk5b & 2 & 0.5 & 1.80 & 1.57 & 7.20 & 0.56 & 2.00 & 0.16 & 0.46 & 0.37 & 4.24 & 1.66 & 1083.26 & -758.25 & 21.20 \\
\hline etk4b & 2 & 1 & 1.39 & 1.23 & 8.43 & 2.22 & 1.17 & 0.31 & 0.25 & 0.22 & 4.31 & 2.31 & 1004.44 & -626.55 & 20.31 \\
\hline etk3b & 2 & 2 & 2.04 & 1.79 & 8.97 & 0.81 & 0.62 & 0.06 & 0.13 & 0.13 & 3.96 & 1.91 & 1319.44 & -523.88 & 19.30 \\
\hline etk2b & 2 & 4 & 2.01 & 1.80 & 10.53 & 2.54 & 0.37 & 0.09 & 0.07 & 0.07 & 3.86 & 1.81 & 1402.78 & -513.87 & 19.70 \\
\hline etk1b & 2 & 8 & 1.54 & 1.33 & 11.11 & 3.11 & 0.19 & 0.05 & 0.04 & 0.04 & 4.57 & 1.60 & 1286.42 & -426.48 & 19.03 \\
\hline et1b & 2 & 24 & 2.35 & 1.98 & 23.13 & 0.38 & 0.13 & 0.01 & 0.04 & 0.04 & 13.97 & 7.42 & 1083.26 & -130.45 & 14.41 \\
\hline
\end{tabular}

Table 3. Textural parameters and growth rates estimated for titanomagnetite. $L_{\max }$ : maximum crystal length, average of 10 largest crystals. $\mathrm{G}_{\max }$ : maximum crystal growth rate, average of 10 largest crystals. $\mathrm{G}_{\text {batch }}$ : crystal growth rate as determined by dividing characteristic crystal size (d) by time. $\mathrm{G}_{\mathrm{CSD}}$ : crystal growth rate estimated from the slope of the crystal size distribution. $\mathrm{d}$ : characteristic crystal size. $\mathrm{L}_{\mathrm{d}}$ : characteristic size determined from the slope of the crystal size distribution. $\mathrm{N}_{\mathrm{A}}$ : area number density. See text for equations defining the parameters. 
Table 1S. Representative microprobe analyses of clinopyroxenes from hydrous and anl

\begin{tabular}{|c|c|c|c|c|c|c|c|c|c|c|}
\hline \# & $\mathrm{SiO}_{2}$ & $\mathrm{TiO}_{2}$ & $\mathrm{Al}_{2} \mathrm{O}_{3}$ & $\mathrm{FeO}$ & $\mathrm{MgO}$ & $\mathrm{CaO}$ & $\mathrm{Na}_{2} \mathrm{O}$ & $\mathrm{K}_{2} \mathrm{O}$ & $\mathrm{Si}$ & $\mathrm{Ti}$ \\
\hline et1a & 44.93 & 1.25 & 10.25 & 9.55 & 12.00 & 19.66 & 0.54 & 0.00 & 1.71 & 0.04 \\
\hline et1a & 44.50 & 1.13 & 9.90 & 9.39 & 12.14 & 19.98 & 0.58 & 0.00 & 1.71 & 0.03 \\
\hline et1a & 45.52 & 1.12 & 9.79 & 9.22 & 12.01 & 20.04 & 0.61 & 0.02 & 1.73 & 0.03 \\
\hline et1a & 44.06 & 1.18 & 10.39 & 9.32 & 11.98 & 20.14 & 0.61 & 0.00 & 1.69 & 0.03 \\
\hline et1a & 45.69 & 1.07 & 9.71 & 8.90 & 12.20 & 20.17 & 0.61 & 0.01 & 1.73 & 0.03 \\
\hline et1a & 44.36 & 1.26 & 10.27 & 9.42 & 11.82 & 20.32 & 0.65 & 0.01 & 1.70 & 0.04 \\
\hline et1a & 44.82 & 1.20 & 10.32 & 9.25 & 11.89 & 20.12 & 0.64 & 0.00 & 1.71 & 0.03 \\
\hline et1a & 45.04 & 1.15 & 10.34 & 9.37 & 11.94 & 19.99 & 0.65 & 0.00 & 1.71 & 0.03 \\
\hline et1a & 44.21 & 1.21 & 10.30 & 9.30 & 11.93 & 19.87 & 0.56 & 0.01 & 1.70 & 0.04 \\
\hline et1a & 45.47 & 1.11 & 9.35 & 8.80 & 12.58 & 20.43 & 0.64 & 0.01 & 1.73 & 0.03 \\
\hline et1a & 46.28 & 1.11 & 9.04 & 8.82 & 12.44 & 20.31 & 0.66 & 0.01 & 1.75 & 0.03 \\
\hline et1a & 44.38 & 1.28 & 10.47 & 9.39 & 11.79 & 20.20 & 0.65 & 0.01 & 1.70 & 0.04 \\
\hline et1a & 45.23 & 1.17 & 9.97 & 9.49 & 12.11 & 19.88 & 0.60 & 0.01 & 1.72 & 0.03 \\
\hline et1a & 45.33 & 1.25 & 10.46 & 9.33 & 11.60 & 20.08 & 0.62 & 0.00 & 1.72 & 0.04 \\
\hline et1a & 44.57 & 1.14 & 10.45 & 9.27 & 11.75 & 20.06 & 0.64 & 0.00 & 1.71 & 0.03 \\
\hline et1a & 45.39 & 1.15 & 9.91 & 9.50 & 12.03 & 20.02 & 0.63 & 0.01 & 1.72 & 0.03 \\
\hline et1a & 45.98 & 1.08 & 9.05 & 8.90 & 12.59 & 20.13 & 0.64 & 0.01 & 1.75 & 0.03 \\
\hline et1a & 44.49 & 1.21 & 10.38 & 9.45 & 11.87 & 19.94 & 0.58 & 0.00 & 1.70 & 0.03 \\
\hline et1a & 44.87 & 1.35 & 10.60 & 9.70 & 11.55 & 20.06 & 0.59 & 0.00 & 1.70 & 0.04 \\
\hline et1a & 46.18 & 1.14 & 9.55 & 9.11 & 12.13 & 20.12 & 0.66 & 0.01 & 1.74 & 0.03 \\
\hline etk1a & 44.38 & 1.29 & 10.09 & 9.95 & 12.48 & 19.51 & 0.65 & 0.01 & 1.70 & 0.04 \\
\hline etk1a & 44.36 & 1.19 & 10.01 & 9.98 & 12.53 & 19.51 & 0.64 & 0.01 & 1.70 & 0.03 \\
\hline etk1a & 45.00 & 1.19 & 9.87 & 9.63 & 12.58 & 19.79 & 0.68 & 0.03 & 1.71 & 0.03 \\
\hline etk1a & 45.00 & 1.15 & 9.81 & 9.73 & 12.57 & 19.41 & 0.64 & 0.03 & 1.72 & 0.03 \\
\hline etk1a & 44.16 & 1.37 & 10.35 & 9.83 & 12.06 & 19.42 & 0.62 & 0.02 & 1.69 & 0.04 \\
\hline etk1a & 44.21 & 1.40 & 10.67 & 9.75 & 12.11 & 19.95 & 0.70 & 0.01 & 1.68 & 0.04 \\
\hline etk1a & 44.26 & 1.28 & 10.41 & 9.59 & 12.09 & 19.86 & 0.65 & 0.01 & 1.69 & 0.04 \\
\hline etk1a & 43.99 & 1.24 & 10.48 & 9.78 & 12.09 & 19.96 & 0.62 & 0.02 & 1.69 & 0.04 \\
\hline etk1a & 44.15 & 1.30 & 10.39 & 9.66 & 12.13 & 20.12 & 0.66 & 0.02 & 1.69 & 0.04 \\
\hline etk1a & 44.36 & 1.29 & 10.39 & 9.64 & 12.07 & 20.02 & 0.61 & 0.01 & 1.69 & 0.04 \\
\hline etk1a & 44.14 & 1.27 & 10.57 & 9.78 & 12.13 & 19.80 & 0.67 & 0.03 & 1.69 & 0.04 \\
\hline etk1a & 45.29 & 1.23 & 9.69 & 9.47 & 12.57 & 19.80 & 0.64 & 0.01 & 1.72 & 0.04 \\
\hline etk1a & 44.73 & 1.33 & 10.04 & 9.68 & 12.41 & 19.88 & 0.62 & 0.01 & 1.70 & 0.04 \\
\hline etk1a & 44.82 & 1.22 & 10.12 & 9.66 & 12.33 & 19.75 & 0.65 & 0.03 & 1.71 & 0.03 \\
\hline etk1a & 44.14 & 1.31 & 10.58 & 9.87 & 11.99 & 19.78 & 0.64 & 0.02 & 1.69 & 0.04 \\
\hline etk1a & 44.42 & 1.25 & 10.36 & 9.64 & 12.17 & 19.85 & 0.62 & 0.02 & 1.70 & 0.04 \\
\hline etk1a & 44.67 & 1.27 & 10.22 & 9.46 & 12.27 & 20.03 & 0.71 & 0.01 & 1.70 & 0.04 \\
\hline etk1a & 44.42 & 1.24 & 10.33 & 9.46 & 12.33 & 19.90 & 0.67 & 0.02 & 1.69 & 0.04 \\
\hline etk1a & 44.81 & 1.17 & 10.40 & 9.58 & 12.32 & 19.87 & 0.71 & 0.01 & 1.70 & 0.03 \\
\hline etk1a & 45.95 & 1.15 & 9.20 & 8.97 & 13.05 & 19.84 & 0.79 & 0.02 & 1.74 & 0.03 \\
\hline
\end{tabular}

